Portland State University

PDXScholar

\title{
"Do I Really Belong Here?" The Effects of Difference in Paths through Higher Education on Graduate Student Perception on Legitimacy
}

Tina Dawn Lillian Burdsall

Portland State University

Follow this and additional works at: https://pdxscholar.library.pdx.edu/open_access_etds

Part of the Sociology Commons

Let us know how access to this document benefits you.

\section{Recommended Citation}

Burdsall, Tina Dawn Lillian, "'Do I Really Belong Here?" The Effects of Difference in Paths through Higher Education on Graduate Student Perception on Legitimacy" (2008). Dissertations and Theses. Paper 2926. https://doi.org/10.15760/etd.2927

This Thesis is brought to you for free and open access. It has been accepted for inclusion in Dissertations and Theses by an authorized administrator of PDXScholar. Please contact us if we can make this document more accessible: pdxscholar@pdx.edu. 


\section{THESIS APPROVAL}

The abstract and thesis of Tina Dawn Lillian Burdsall for the Master of Science in Sociology were presented August 5, 2008, and accepted by the thesis committee and the department.

COMMITTEE APPROVALS:

Pete eollier, Chair

\section{Rbbert Liebman}

Matthew Carlson

DEPARTMENT APPROVAL:

Veronica Dujon, Chair

Department of Sociology 


\section{ABSTRACT}

An abstract of the thesis of Tina Dawn Lillian Burdsall for the Master of Science in Sociology presented August 5, 2008.

Title: Do I Really Belong Here?: The Effects of Difference in Path Through Higher Education on Graduate Student Perception on Legitimacy

Why do some master's level students feel confident in completing their programs and some do not? Why do some feel connected to their department and some do not? Why do some feel legitimate as graduate students and some do not? This research proposes that there may be differences in how master's students understand the graduate student role based on whether they went directly from high-school through their bachelor's to their master's, or if they took time off between their bachelor's and master's program. This thesis used in-depth interviews with twelve second-year master's students at Portland State University to explore these questions: six with students who had a linear trajectory through higher education and six with students who had a break after completing their bachelor's and before returning for their master's (broken trajectory students).

Students from both groups began their programs with questions about their ability to perform at a master's level. Broken trajectory students were more likely to 
have thought through their chances of success and entered their programs 'knowing' that they would successfully complete the programs even when they questioned their academic abilities. Students from both groups overall felt a progressive increase in feelings of connection to their departments. The linear trajectory students entered their programs with some established feelings of connection with other graduate students. The broken trajectory students did not have these established connections, but desired connection with other serious students. Overall, students from both groups experienced increased feelings of legitimacy as graduate students, but the criteria by which they judged their legitimacy differed between groups. Linear trajectory students used academic ability as a primary measure of legitimacy, where broken trajectory students used having a clear understanding of why they were in graduate school as the standard to determine whether they "belonged in college." The two groups also differed in the source of their student role standard: broken trajectory students used professors as their role reference group, whereas the linear trajectory students used peers and undergraduate students. This thesis closes with a discussion of the implications of this research for theory, programs, and current models of persistence. 


\section{'DO I REALLY BELONG HERE?'}

THE EFFECTS OF DIFFERENCE IN PATHS THROUGH HIGHER EDUCATION ON GRADUATE STUDENT PERCEPTION ON LEGITIMACY

by

TINA DAWN LILLIAN ̧RSALL

A thesis submitted in partial fulfillment of the requirements for the degree of

MASTER OF SCIENCE

in

SOCIOLOGY

Portland State University

2008 


\section{ACKNOWLEDGEMENTS}

The process of going back to school, doing this research and writing this thesis has proven to me how lucky I am to have the people in my life that I do. My journey through my master's program has only been possible because of the immense support that I have had. My committee, who never gave up on me, and continually requested my best, has been instrumental with their guidance. My colleagues, especially Robin, Carolyn, and Angie, with whom I spent many hours arguing theory and discussing research have been responsible for keeping me sane. My mother Helle Girey, father George Girey, and sister Linda Gordon have been life-long role models. I attribute my courage to even start on this adventure to them.

Most of all, I need to acknowledge the amazing support that I received from my family. My husband Derek, and daughters Nicole and Robin, have never waivered in their belief in me. Their encouragement and love sustained me throughout this process. Thank you for being family, in the best sense of the word. 
ACKNOWLEDGEMENTS _ i

LIST OF TABLES ' iv

LIST OF FIGURES $\quad$ v

CHAPTER 1: INTRODUCTION 1

CHAPTER 2: LITERATURE REVIEW AND THEORETICAL BASIS 6

Adult Experiences in Higher Education $\quad 6$

Involvement and Connection $\quad 8$

$\begin{array}{ll}\text { Identity and Attribution } & 17\end{array}$

$\begin{array}{ll}\text { Research Questions } & 25\end{array}$

CHAPTER 3: METHODS . $\quad 27$

$\begin{array}{ll}\text { Setting } & 27\end{array}$

Project Design $\quad 27$

Participants $\quad 29$

Data Collection Methods $\quad 32$

Interview Tool $\quad 33$

Confidentiality $\quad 36$

Potential for Bias $\quad 37$

Method of Analysis $\quad 39$

CHAPTER 4: RESULTS $\quad 43$

Themes within Traditional / Linear Trajectory Group $\quad 44$

Support $\quad 44$

Confidence in Completing Program 49

Feeling of Connection to Department $\quad 51$

Feeling of Legitimacy as Graduate Student $\quad 54$

Themes within Broken Trajectory Group $\quad 57$

$\begin{array}{ll}\text { Support } & 57\end{array}$

Confidence in Completing Program 61

Feeling of Connection to Department 63

Feeling of Legitimacy as Graduate Student $\quad 65$

Similarities between Groups $\quad 67$

$\begin{array}{ll}\text { Support } & 67\end{array}$

Feeling of Connection to Department $\quad 67$ 
Differences between Groups $\quad 68$

$\begin{array}{ll}\text { Support } & 68\end{array}$

Confidence in Completing Program $\quad 72$

Feeling of Connection to Department 73

Feeling of Legitimacy as Graduate Student $\quad 75$

CHAPTER 5: DISCUSSION

Confidence in Completing Program $\quad 80$

Feeling of Connection to Department $\quad 88$

Feeling of Legitimacy as Graduate Student $\quad 96$

Knowledge of Graduate Student Role 103

CHAPTER 6: CONCLUSION 108

Issues of Differences in Perception of Legitimacy and Student Success 111

Issues of Differences in Goals and Choices of Role Standards $\quad 114$

Benefits of Combining Methods of Qualitative Analysis 114

Theory Level Implications $\quad 115$

Implications for Models of Persistence $\quad 117$

Program Level Implications $\quad 118$

$\begin{array}{ll}\text { Limitations } & 120\end{array}$

Future Research $\quad 122$

$\begin{array}{ll}\text { REFERENCES } & 125\end{array}$

APPENDIX I: INTERVIEW GUIDE 132

APPENDIX II: GRAPHS 136

$\begin{array}{ll}\text { APPENDIX III: SURVEY } & 140\end{array}$

APPENDIX IV: INFORMED CONSENT FORM 142 


\section{LIST OF TABLES}

TABLE 1: PARTICIPANT IDENTIFICATION CODES: LINEAR 37

TABLE 2: PARTICIPANT IDENTIFICATION CODES: BROKEN 


\section{LIST OF FIGURES}

FIGURE 1: TINTO'S MODEL

FIGURE 2: BURKE'S MODEL

FIGURE 3: WEINER'S MODEL

FIGURE 4: LINEAR TRAJECTORY CONFIDENCE

FIGURE 5: LINEAR TRAJECTORY CONNECTION

FIGURE 6: LINEAR TRAJECTORY LEGITIMACY

FIGURE 7: BROKEN TRAJECTORY CONFIDENCE

FIGURE 8: BROKEN TRAJECTORY CONNECTION

FIGURE 9: BROKEN TRAJECTORY LEGITIMACY

FIGURE 10: COMBINED CONNECTION

FIGURE 11: COMBINED CONFIDENCE

FIGURE 12: COMBINED LEGITIMACY

FIGURE 13: CONFIDENCE IN COMPLETING PROGRAM

FIGURE 14: FEELINGS OF CONNECTION

FIGURE 15: FEELINGS OF LEGITIMACY 


\section{CHAPTER 1: Introduction}

This thesis will explore how students understand and experience their time in a master's degree program by comparing two groups of students' perceptions of their relative levels of confidence in completing their program, connection to their department, and feelings of legitimacy. Why do some master's students feel confident about completing the program they are in and some do not? Why do some master's students feel a sense of connection to their department and some do not? Why do some students feel a sense of legitimacy as graduate students and some do not? The two groups of students examined in this research are: broken trajectory students, those who have taken a break in their education, and traditional / linear trajectory students, those who have moved directly through their educational paths. The experiences of these two groups of students will be compared to explore possible differences in their adjustments and experiences in graduate education. By doing so, this research potentially can help fill-in the gaps in the literature related to both returning students as well as to graduate students.

The United States is rapidly moving towards being a knowledge society, where people with higher education degrees are able to make more money and have more flexibility in their careers than those without such credentials (Powell and Snellman, 2004). This has led to a sharp increase in the numbers of adults in higher education. This increase reflects society's changing attitudes towards the importance of college credentials as it relates to work stability, financial stability and other life opportunities (Kasworm, 2003). The National Center for Educational Statistics projects that by 2014 
students over the age of 24 will be the fastest growing population on university campuses across the United States. Research on higher education has not kept up with the changing demographics and both universities and students are now being faced with unexpected situational, institutional, and personal barriers to degree completion (Tinto, 1998).

While an increasing number of higher education studies are focusing on various non-traditional students (such as first generation or minority students), older and returning students remain understudied (Pusser, Breneman, Gansneder, Kohl, Levin, Milam, and Turner, 2007). When studies do include older and returning students, many put adults in the non-traditional category along with part-time students, minorities, commuters, first generation students, and students who work full time (e.g. Lundberg, 2003). While this broad category is important to consider, it does not allow us to look at the separate groups and how they have different needs and experiences.

The cliché that "masters are the new bachelors" reflects the increasing importance of the master's level degree in our society. Yet the higher education literature on returning students focuses almost exclusively on undergraduates (Sissel, Hansman, and Kasworm, 2001; Kasworm, 2003; Lundberg, 2003). Although academia has traditionally devalued the master's level degree in comparison to the Ph.D. level degree (Giordano, 2000; Gaylord, 2000) the credential and pragmatic skills gained by earning this degree are more useful for those wishing to enter the working world than ever before. Promotion and pay are linked in many businesses to higher education credentials, such as a master's degree (Fairfield, 2007; Pusser et al., 
2007). But, there is an insufficient literature base about the graduate school experience, particularly for returning students.

This research seeks to understand the relationships among students' feelings of connection to their master's programs, understanding of the graduate student role, feelings of legitimacy as graduate students and estimated likelihood of completing their degree program. The importance of students' connection to their college or university has been identified as one explanatory factor in models of undergraduate student retention (e.g. Tinto, 1987, 1988; Astin, 1999). Relationships with peers, professors, and administrators can have a major influence on a student's success or failure in higher education. But the undergraduate models of retention do not examine how students' feelings of connection to their specific programs influence degree completion. Therefore this research employs a qualitative methodology, in-depth interviews, to investigate the students' experience in their master's programs. Using this qualitative approach provides depth to the analysis by allowing the students to present their personal stories and experiences in their own words.

This research will use identity theory to discuss how graduate students develop their understanding of the graduate student role through interactions with their peers, professors and others in the academic arena. Identity theory posits that individuals come to understand themselves through categorizing other people, as well as themselves, based on the interactions that they have (McCall and Simmons, 1966). This then suggests that graduate students will come to understand themselves as graduate students based on their interactions with professors, peers, and other 
significant people. Identity Control Theory (Burke, 1991) further develops this idea by examining the processes through which this self identification in terms of a role occurs, specifically how an individual modifies her behaviors in order to reduce the discrepancy between the her understanding of herself in terms of a specific role and the feedback that she receives about her actual role-associated behavior. In addition, it is proposed that, due to the existence of multiple reference groups, different students may internalize slightly different standards for the same role, due to differences in the group they see themselves as being part of (Collier, 2001).

Just as the feedback from others influences whether a student feels she is successfully enacting a role, how that same student understands her success or failure in role enactment impacts whether she continues to proceed in the manner that she was using to reduce the self-standard / feedback discrepancy (Hunter and Barker, 1987). Attribution theory helps frame this concept in regards to how graduate students perceive their likelihood and ability to succeed. Misattributing the reasons for success or failure in regards to specific tasks in graduate school can affect the likelihood of degree completion. An extreme form of misattribution, the Imposter Phenomenon (Clance and Imes, 1978), will be discussed in relation to students' feelings of legitimacy in their master's program.

This study investigates whether feelings of confidence in completing their program, connection to their departments, legitimacy, and role internalization influence graduate students' success in master's degree programs. It asks whether these factors are influenced by relationships with professors, peers and outside 
support. In particular, it asks whether these factors differ for students who have taken a break in their educational path.

The next chapter will review the relevant literature on adult experiences in higher education, as well as the theoretical perspectives used in this study. Chapter three will discuss the methodology used in designing and implementing this research. Chapter four will focus on the key findings, while chapter five will discuss the implications of these findings in regards to the research questions. The final chapter will be the conclusion which will include limitations, future areas of research and how the findings can be applied towards helping students achieve success in graduate school. 


\section{CHAPTER 2: Literature Review and Theoretical Basis}

This literature review is divided into four major sections. The first section discusses the literature about adult experiences in higher education. The second section discusses how relationships, or the lack thereof, impact experiences in higher education. The third section contains a discussion of identity theory, attribution theory and an overview of the imposter phenomenon literature. The fourth, and last, section presents the research questions.

\section{Adult experiences in higher education}

In years past, students who were fortunate enough to be able to pursue higher education had their lives planned out for them. Traditionally, they would graduate from high-school, immediately enter college, complete their bachelor's degrees, perhaps go on to earn graduate degrees, and then find jobs to work at until retirement. This "standard" path put students at specific points of their education at specific points in their life. Based on this model, students in college were expected to be young, and colleges were set up with these students in mind (Sissel et al., 2001; Quinnan, 1997).

As times have changed, so have college demographics. More adults are returning to college (Merriam, Caffarella, and Baumgartner, 2007; Sissel et al., 2001) yet colleges and universities expect the path designed for "traditional" students to work equally well for returning adult students. The reasons these adults are returning to school vary: to train for a new career, to be eligible for advancement in their current 
career, because of life transitions (e.g. death of spouse, children leaving home, being laid-off from work), as well as for personal satisfaction (Merriam et al., 2007;

Plimmer and Schmidt, 2007; Aycock, 2003; Pascarella and Terenzini, 1991; Witherspoon and Nickell, 1991).

Adult students who return to school may have difficulties in transitioning into the student role and integrating into their departments that are different than the difficulties faced by traditionally aged students (Witherspoon and Nickell, 1991; Sissel et al. 2001). These adult students often have additional responsibilities and demands on their time, such as children, family, and careers. This limits the availability of these students to interact with faculty and peers as well as limiting the opportunity to take advantage of resources such as tutoring centers and the library. The conflict between their other roles and the new student role may lead returning students to abandon their educational goals (Witherspoon and Nickell, 1991). Cross defines these additional challenges that adults may face as situational, institutional, and dispositional barriers (Cross in Aycock, 2003). Examples include such things as social responsibilities that preclude the adult learner from academic activities (a situational barrier), inconvenient hours for university resources (an institutional barrier), or the personal fear of being too old (a dispositional barrier). Some returning students may also feel that the academic culture of colleges is antagonistic to adult learners. This is based on the combination of the challenges that these student's face at the university and the perceived attitude within higher education that they are not as good "academic investments" as younger students due to the limited societal returns expected from 
them based on their fewer productive years remaining in the workforce (Quinnan, 1997).

O'Donnell and Tobell (2007) interviewed adult students enrolled in a program for 'mature students' to learn more about these students' transitions to higher education in terms of how they experienced learning, educational practices, and higher education participation, as well as the effects of college participation on students' identities. The researchers found that adult students are aware of, and think about, the educational system that they are in. The students' understanding of, and reactions to, system practices "underpin identity shifts that enable participation" (O'Donell and Tobel, 2007: 326) in their education.

\section{Involvement and Connection}

Making transitions into and within higher education are challenging for all students and the degree to which they feel involved and connected to their colleges or universities seems to be of critical importance.

\section{Models of Undergraduate Persistence}

For many undergraduates college may be the first time that they have lived on their own, juggled expenses and interacted with a diverse mix of students and faculty. Because of the importance of this transition for academic and social success, there have been many studies on student persistence and departure at the undergraduate

\footnotetext{
${ }^{1}$ These students were adults who did not have the high school qualifications needed to get into college. The participants in their study were between the ages of 23 and 57 years old.
} 
level (e.g. Tinto, 1988; 1998; Astin, 1984, 1993, 1999). This body of research has shown that both academic and social involvement play key parts in keeping students in college. Academic involvement refers to "the amount of physical and psychological energy that the student devotes to the academic experience" (Astin, 1999: 518) in areas such as studying, reading and attending lectures. Social involvement would include areas such as discussions and relationships with peers and interactions with professors.

Astin's $(1984,1993,1999)$ model of student involvement postulates that student success (defined as both student learning and as personal development) is directly influenced by the amount of time that the student is involved in the academic environment. This theory is based on the pragmatic concept that what the student actually does is what is important. Student time is the key criterion for determining what the student can achieve in terms of realizing developmental goals. If the student's goal is to develop academic and social competence in a subject then the more time the student spends reading about the subject, talking to peers and professors about that subject or listening to lectures about that subject, the greater her gains will be in increasing her knowledge and understanding.

According to Astin, key factors affecting student persistence in college include place of residence, participation in extracurricular activities, working part-time on campus, being enrolled full-time, being enrolled in a four-year college, and having a strong student-college 'fit' (Astin, 1984: 523-524). The importance of each of these factors makes sense within Astin's involvement framework: students who live, play 
and work on campus have more time on the campus to devote to academic and other campus activities and will be more likely to be around others who will support their involvement. The more time students participate at the college, at whatever level, the greater the sense of attachment the student will feel to the college. While all forms of involvement play a role in student satisfaction and persistence, the frequency of interactions between students and faculty turns out to have the strongest impact on student satisfaction:

"Students who interact frequently with faculty members are more likely than other students to express satisfaction with all aspects of their institutional experience, including student friendships, variety of courses, intellectual environment, and even the administration of the institution" (Astin, 1999: $525)$.

Tinto (1975) created a conceptual model of dropout from college (see figure 1). According to this model, all students enter college with individual attributes, family background, and previous schooling experiences that impact the student's commitments to education. There are two primary commitments that impact student's successful completion of college. The first goal commitment refers to the student's commitment to 


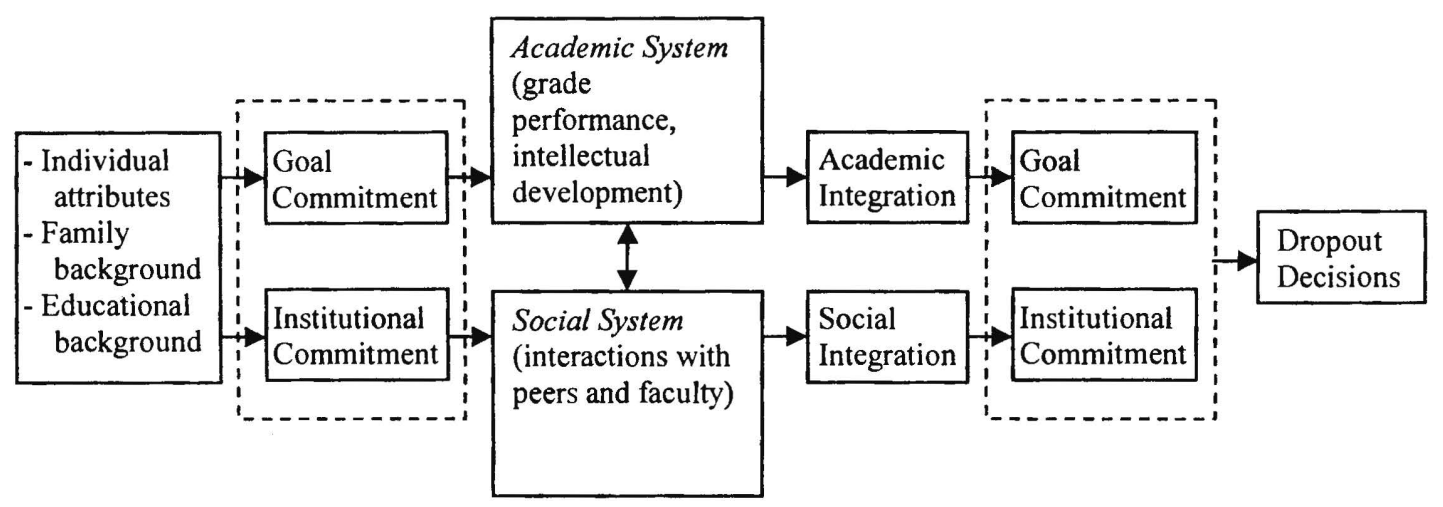

complete college. A student who is determined to complete college is more likely to do so than a student who is apathetic to that goal. The second is institutional commitment, which refers to the student's loyalty to complete a degree at the particular institution that they are enrolled in. A student who is committed to a particular institution is more likely to remain at that institution than a student who is indifferent to that particular institution. According to Tinto, students' persistence may be grounded in either, or both, the academic and the social system of the college (Tinto, 1988: 448). The student's performance in the academic system, typically measured by grades and personal intellectual development, and their experiences in the social system, in the form of peergroup and outside-of-class faculty interactions, can reinforce or diminish feelings of connection and therefore both goal and institutional commitments.

Tinto (1988) also discusses the importance of looking at the temporal quality of student departure. Using social anthropology and the concepts of rites of passages, Tinto proposes that students' successful transitions to the university require three 
major passages: separation, transition, and incorporation (1988). Separation entails students breaking away from the memberships and customs of their past in order to allow for the adoption of the academic and social norms of their new environment. Transition occurs as the past is separated from, but before the new norms are fully incorporated. Incorporation involves not only adopting the norms of the new environment, but also creating strong relationships with the new community. If there is a failure at any of these passages, the transition becomes impaired - students become disengaged or leave the academic setting altogether (Tinto, 1988).

Mentoring has been previously identified as a key element in student development (e.g. Keith and Moore, 1995; Chickering and Reisser, 1993; Pascarella and Terenzini, 1991), and can help explain the indirect connection between relationships with faculty and degree progress through the impact that mentoring can have on both the personal and intellectual integration of students. Rosenbaum (1986) (in Keith and Moore 1995), uses a tournament model to explain how ability is created by both demonstrated success as well as structural opportunities, such as mentoring, that allow for further performances to demonstrate success: "opportunities to demonstrate ability occur within a critical period, during which time the organization may identify a student's ability and decide whether additional opportunities will be provided" (Keith and Moore, 1995: 200).

Peers have consistently been identified as vital for traditional students' college success (Astin, 1993; Pascarella and Terenzini, 1991). Peer relationships also play an important role in student success as they contribute to Tinto's social and academic 
integration (Chickering and Reisser, 1993; Pascarella and Terenzini, 1991). Peers can be sounding boards for ideas as well for actions. Students not only learn about course material from one another by discussing and clarifying academic concepts, they also learn how to successfully interact with professors and what it takes to be considered a legitimate graduate student:

"It is the student culture that principally defines the appropriate responses to institutional authority and accepted ways of interacting with faculty. Faculty-student relationships are encouraged or blocked by word-of-mouth information about who is a good adviser, a dynamic teacher, or a hard grader" (Chickering and Reisser, 1993: 395).

\section{Models of Undergraduate Persistence and Adult Students}

Astin's involvement theory leads to a "zero-sum" situation, where the more activities or responsibilities that a student has that draws their efforts off-campus, the less energy and time the student will have for involvement on campus, leading to a negative effect on student learning (Astin,1999: 523). Students who have outside commitments such as a family or a full-time job will have less time and energy for involvement in the academic arena of the college campus and therefore are less likely to develop academically and socially. This model would suggest that adult students face additional challenges with regard to establishing the high levels of campus involvement associated with student success. 
Astin's theory is attractive in that it is relatively easy to understand, and makes common sense, however it may have limited applicability to adult learners as it is focused on traditionally aged students. In a study of the relationship among key integration variables from Astin's model and student age, Lundberg (2003) found support for Astin's model in that all age groups were positively affected by the social and academic integration variables of: peer teaching, peer discussion, faculty interaction, and quality of relationships with faculty and administrators and negatively affected by part-time enrollment. Lundberg also found that students 29 and younger were negatively affected by working off-campus and by commuting, but not students over the age of 30 . Lundberg also found that it was only the educationally-related peer relationships that were influential for students over the age of 30 , whereas for younger students both the social and the educational peer relationships proved important (2003). Interestingly, Lundberg did not limit her definition of peer to school peers. She defined peers as coming from any area (such as work, the neighborhood, the classroom); their defining characteristic was that they engaged in discussing academic concepts with the student.

\section{Models of Graduate Student Persistence}

While current models of undergraduate persistence and departure are appropriate exemplars to begin the exploration of master's level graduate persistence, it is still important to recognize that there are significant differences between the undergraduate and graduate experiences (Tinto, 1987), as well as between the master's 
level and doctoral level experiences (Girves and Wemmerus, 1988). For graduate students, the transition may instigate a struggle to balance competing responsibilities. Undergraduate academic success generally consists of doing well by attending classes and doing well on assignments and tests. This is in contrast to the graduate level where success is linked to different skills and activities such as group and independent research and personal engagement with faculty and peers (Guevara, 2006).

Tinto (1993: 231), in a discussion regarding a possible longitudinal model of doctoral persistence, acknowledges that it is conceivable that undergraduate and doctoral persistence would have some similarities, especially in the areas of the social and academic systems of the institution. Still he recognizes that his model of student persistence is not entirely applicable when explaining graduate student persistence: "Unlike undergraduate persistence, the process of graduate persistence can not be easily described by any one simple model. This is the case because models of graduate persistence are likely to differ somewhat across fields of study and across periods of time. The factors that appear significant at one stage of persistence may not be significant later on. And some factors, like student-faculty interaction, may change over time in the manner in which they influence persistence." (Tinto, 1993: 238)

Some researchers have argued that Tinto's models of persistence are applicable to master's level students (Zoltanski, 1995). By combining Tinto's undergraduate model of persistence with his discussion of doctoral persistence, Zoltanski claimed that the modified model was appropriate to frame the discussion of master's student 
retention. Other researchers (e.g. Guevara, 2006) have agreed with Tinto's assessment that there are significant differences between undergraduate, master's and doctoral students' experiences and therefore the models are not sufficient to discuss master's level student retention.

Girves and Wemmerus (1988) developed a social support model of graduate student degree progress building on Tinto's model. For master's students, grades, department characteristics and student characteristics all directly influenced degree progress. Students' relationships to faculty were indirectly involved with degree progress because they received encouragement through their relationships with faculty. It is also possible that the more capable students were more likely to seek out faculty relationships and therefore the students with better relationships with faculty were more likely to have higher grades (Girves and Wemmerus, 1988; 184).

Graduate students' academic and social involvement at the university is still very important, but the groups of people that most influence their daily interactions are different from those that are influential for undergraduate students (Tinto, 1987). Undergraduate students use their professors, peers, and members of the general college community as their primary points of reference. Graduate students, at least at the doctoral level, have academic reference groups that are generally confined to the students and faculty within their program on one hand and the broader professional population on the other (Tinto, 1993; Girves and Wemmerus, 1988). As Tinto states: "the process of graduate persistence at the doctoral level can be understood as being analogous to the conversations sociologists have about processes of socialization to 
work and the role normative reference groups play in that process" (Tinto, 1993: 233). While this makes intellectual sense, it currently is "merely informed speculation" (Tinto, 1987: 241). With this in mind, turning to the literature on role and identities may further help explain the processes of graduate student transition.

\section{Identity and Attribution}

Identity Theory is derived from Symbolic Interactionism, particularly the work of George Herbert Mead. Mead theorized that individuals define themselves through participation in social acts, or the 'conversation of gestures' (Mead, 1934: 167). The basis of the theory is that the identification and development of shared understandings of the meaning of people and things are the foundation upon which an understanding of society is built (Mead, 1934). Identity theory "proceeds by doing with respect to the structure of role relationships and to self what symbolic interactionism does with respect to the full range of possible social psychological variables." (Stryker and Serpe, 1982: 200). People, including the self, are placed in internal categories dependant upon their social positions which help determine how interactions should be enacted. Roles are not fixed, but can change depending upon these interactions and the consequent interpretations (McCall and Simmons, 1966).

Roles and identities are used to direct both the individual and the collective levels of social behavior. Stryker (1982) uses the concepts of identities, identity salience and commitment to understand the choices individuals make in role behaviors when there are other reasonable courses of action that could have been taken. 
Identities are created through reflexively applied cognitions regarding role interactions in social relations. Identity salience refers to the importance hierarchy that individuals place their identities in. The higher the salience, the more likely a person is to enact that identity. Commitment refers to how much a relationship with a social group or other individuals depends upon the person adopting that identity (Stryker, 1982). High commitment levels encourage the creation of relevant social groups or networks and limit interaction with irrelevant groups.

Burke's Identity Control Theory (1991) provides insights into the processes that underlie identity acquisition and enactment. According to Burke (1991), identity formation is a continuous and active process that can be thought of as a discrepancyreducing feedback loop. According to Burke's model, the process that people use to develop and understand their identity is a 'control system.' This control system, or feedback loop, is enacted whenever an identity is activated through interactions with other people who are significant to the role (see figure 2). An identity is defined as "a set of 'meanings' applied to the self in a social role or situation defining what it means to be who one is" (Burke, 1991; 837). This "set of meanings" is the standard that the person uses to help define who she is. In other words, this standard is the set of expectations that are in the form of meanings for an identity (Burke, 1996; 7). Where this standard comes from is not entirely clear, but Burke has proposed that it may come from prior socialization (Tushima and Burke, 1999), from the 'ought-self guide,' or the 'ideal-self guide' (Burke, 1996; 12), or from higher-level identity standards or principle level standards (Tushima and Burke, 1999). The standard for the enacted 
role is compared to the input: the person's perceived self-meaning, or 'reflected appraisal,' derived from the social interaction (Burke 1991, 1996). When there is a discrepancy between the standard that a person holds and the input, the person feels distress. This distress is in proportion to the amount of perceived discrepancy. The person then modifies their output, or their meaningful behaviors, in order to attempt to bring the input into alignment with their standard. In familiar situations, this model is automatic and output is adjusted to minimize any discrepancy found without the individual's conscious thought. When the input does not match the standard, behavior is changed. Congruence between standard and input is not spontaneous; people update and vary their output constantly in order to maintain congruent feedback in order to minimize feelings of distress and to legitimate the standards that they are using for the role. 


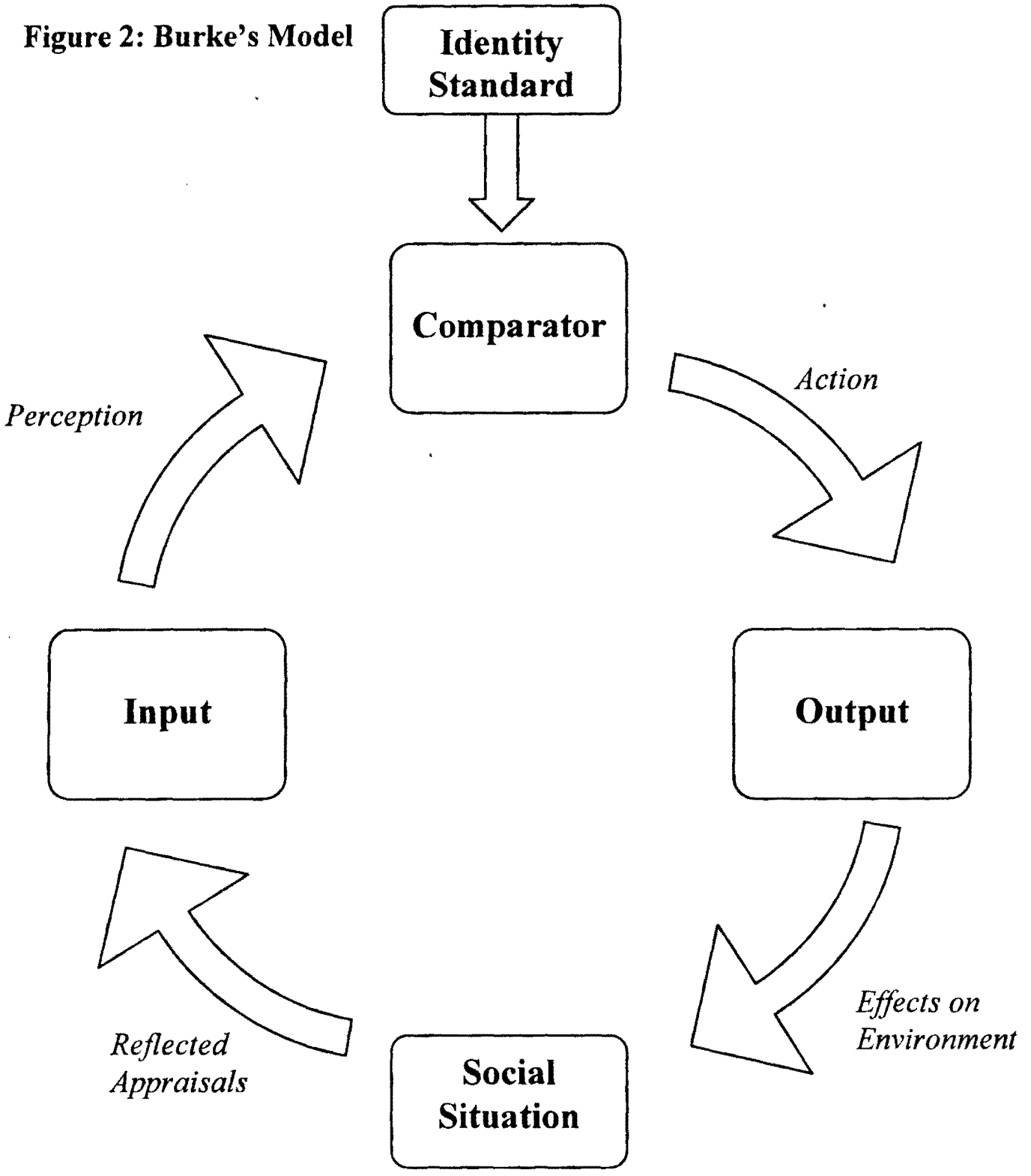

Burke (1991) identifies four identity interruptions, which are situations that cause distress because they create perceived discrepancies between a person's standard and their output. These are broken loop, interference from other identities, over-controlled identity system and episodic identities (Burke, 1991: 841-844). 
'Broken loop' refers to an interruption in the automatic adjustment of the control system caused by outside influences (Burke, 1991: 841). If the interruption is at the output stage (see figure 1), when the person is enacting a role related behavior, it may be that others are not paying attention to the person's behaviors or that the behaviors are not having any effect on them. If the break is at the input stage, when the person is evaluating the responses they got as a result of their role related behaviors, then it may be that the behaviors are having an effect, but it is not the anticipated or expected one. The 'others' in this case may be perceiving the behavior incorrectly, they may misunderstand the behavior, or the feedback from them is being mistaken by the receiving individual (Burke, 1991; 841-842).

This last case, where the feedback is being mistaken by the receiving individual can be further broken down. The receiving individual may be misrecognizing the symbol, such as not understanding jargon being used, or they may be misattributing the reasons for feedback that they are receiving. This last point is important in that even though the individual's role-related actions have been effective in eliciting feedback, they misrecognize positive feedback as sarcasm or criticism.

Collier's Differentiated Model of Role Identity Acquisition (2001) further develops Burke's model by proposing that there are multiple dimensions involved in understanding role creation. Identity formation is not just based on the interaction with a generic 'other,' but is based on: "similar others for whom the role is 'real' based on their experience in using that role as a resource to get actual group-valued tasks accomplished" (Collier, 2001: 220). Different reference groups will emphasize 
different weighting of role dimensions based on what interactive goals the members of that group are trying to accomplish. As there can be multiple reference groups, the particular reference group an individual uses is important in determining what dimensions of the role standard become important to that person in trying to be validated in the role. This means that two individuals, who are using the standards of different reference groups with regard to enacting the same role, might highlight different behaviors in an effort to get feedback that they are matching the standards of their respective reference groups (Collier, 2001).

Attribution theory attempts to explain the inferences that people make about what causes the behavior of themselves or others (Bar-Tal, 1978: 259). Weiner (1974) suggested that what an individual believes about the causes of personal successes and failures are important to understand when looking at the achievement related behaviors of individuals. He proposed an attributional model which posits that the beliefs that a person has about the reasons for their success and failure mediates their behavior between the individuals perception of an achievement related event and the outcome. These reasons can be dichotomized in terms of three dimensions: locus of control -internal or external, controllability -- controllable or uncontrollable, and stability -stable over time or variable (see figure 3) (Weiner, 1972,1979). The internal/external dimension refers to perceived source of the success or failure. Things such as ability and effort are considered internal because they originate inside the person. Luck and task difficulty are considered external because they originate outside of the person (Weiner, 1979). The controllable/uncontrollable dimension refers to the ability of the 
person to control the outcome: effort is controllable, whereas luck is not. Stability over time versus variability refers to the likelihood that the outcome would be different at a different time: effort and luck can both change over time, but ability is seen as a stable internal dimension (Weiner, 1972, 1979; Bar-Tal, 1978).

According to Bar-Tal (1978), how people attribute their successes and failures in regards to these dimensions affects their affective and cognitive reactions to the outcomes. If a person succeeds and attributes this success to their ability, which is an internal-stable cause, her affective reaction will be increased pride (based on the internal dimension of ability) and her cognitive reaction will be to expect similar performances in the future (based on the stable dimension of ability). If a person fails and attributes this failure to their ability, which

Figure 3: Weiner's Model Internal External

\section{Controllable}

\section{Uncontrollable}

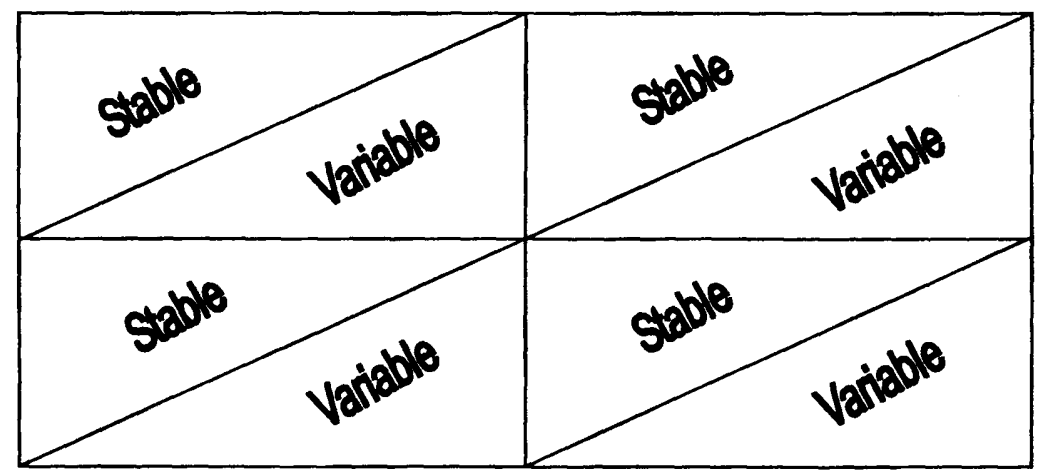

is still an internal-stable cause, his affective reaction will be increased shame (based on the internal dimension), but based on the stable dimension, the cognitive reaction will remain that he expects similar performances in the future. In situations where the outcome is attributed to an unstable cause, the cognitive reaction will be that the outcome could change in future performances. In situations where the outcome is 
attributed to an external cause, the affective reaction is to decrease pride in successful situations, and to decrease shame in failure ones (Bar-Tal, 1978). For example, if a person fails but attributes it to luck, which is an external-unstable cause, she will feel less shame and believe that the next time that she is in this situation she may be successful.

The phrase, "imposter phenomenon," was originally coined by Pauline Clance and Suzanne Imes (1978) in a discussion of their research on therapy issues of highachieving women. The imposter phenomenon refers to the feelings of fraudulence that these women experienced in connection to the successes that they experienced in their lives (Clance and Imes, 1978). Clance and Imes (1978) posited these feelings of fraudulence to be based on the inability of these women to attribute personal success to their own natural ability. The individual then suffers feelings of inadequacy or stress due to attributing success to qualities such as effort, luck, or personality traits such as charm. In the imposter phenomena the individual misattributes the positive feedback to personal qualities or other factors that are not associated with the role in question. In the end, what counts the most is not the source for the alternative attribution so much as the denial that successful performance of the role is the source of the positive evaluation. In other words, even if impostors do well from everyone else's point of view, they still consider themselves to lack the relevant role-related skills.

The student who suffers from the imposter phenomena may be perceived as an " $A$ " student by her professors and peers, but the grades and praises are misattributed to 
be the result of factors that do not validate her understanding of herself as a competent student. Instead the grades and praises may be seen as further proof that the student "fooled" everyone and that the student is bound to be exposed as incompetent and unqualified to be in school.

The literatures on involvement, student persistence, identity acquisition, interrupted identities, attribution theory and the imposter phenomenon all contribute to the foundation for the current research. This study will explore how students perceive their experiences in master's programs and how these perceptions affect the students' understanding of themselves as graduate students, including whether they think they are likely to complete their respective degree programs.

\section{Research Questions}

This research will address four research questions relating to different aspects of adult students' experiences in graduate school.

1) How do the experiences of two groups of masters students - one group who followed a traditional path (i.e. linear trajectory) and another group who took a break in their education prior to starting graduate school (i.e. broken trajectory) -- affect students' confidence in their ability to complete the program? 
2) How do differences in the educational path that master's students take affect students' feelings of connection to their program?

3) How do differences in the educational path that master's students take affect students' perception of legitimacy?

4) How do differences in the educational path that master's students take affect these students' knowledge of the graduate student role?

\section{Conclusion}

This chapter discussed the pertinent literature for this study in the areas of adult experiences in higher education, theoretical models of social and academic integration, identity theory attribution theory, and the imposter phenomenon. The following chapter will outline the methodology used in this study. 


\section{Chapter 3: Methods}

This chapter provides an overview of the setting of the research, participant characteristics, the project design and the interview tool. Issues of confidentiality and bias are addressed and a brief description of the method of analysis is provided.

\section{Setting}

This research was conducted at Portland State University, a four-year public university in Portland, Oregon. PSU students are primarily non-residential. The average age of newly enrolled master's students for fall term 2006 was 30.6 years old. In winter term $2008,60 \%$ of graduate students identify themselves as women, $40 \%$ as men. $68 \%$ of graduate students classify themselves as white (non-Hispanic), $12 \%$ classify themselves as a racial or ethnic minority, $10 \%$ are international students, and $10 \%$ are other or unknown (PSU Office of Institutional Research and Planning, 2008).

\section{Project Design}

Overview

This study was exploratory in structure. Qualitative methods were used to collect and analyze the data as this allows for greater in-depth investigations of personal experiences. This study sought to understand the personal insights and experiences of the students themselves: "the goal is not to generalize to predict and control but rather to describe what people do and say within local contexts. These particularistic generalizations or assertions on the basis of the direct experience of 
observation and interviewing... are the goal of much qualitative work" (Freeman, daMarrais, Preusske, Roulston, and St. Pierre, 2007: 29).

Design

This study used a comparative design, wherein the graduate school transition experiences of two groups of Portland State students - one group that went directly from high-school into graduate school, and a second group of students each of whom took a break in their education before entering a master's program. The students in the first group could be said to be following a linear trajectory, while those in the second group more closely followed a broken trajectory.

The original research design called for eighteen interviews to be completed, nine with students who have gone directly from high school through to graduate school, and nine with students who took a break in their education before entering a master's program. This number is based on studies that have done other student comparisons in a preliminary literature review (Aycock, 2003; O'Donnell and Tobbell, 2007). During the course of data collection, this design was changed, due to persistent recruitment issues, so that a total of twelve students were interviewed - six who have gone directly from high school through into graduate school, and six with students who took a break in their education before entering a master's program. Issues with participant recruitment are addressed later in this chapter.

The final number of interviews for this research was twelve. Because this is a qualitative study, it is not the number of interviews in a group but how quickly and 
completely saturation is achieved. Saturation is defined as "data adequacy" (Denzin and Lincoln, 2005: 529) where the data being collected is no longer providing new information or categories (Bryant and Charmaz, 2007: 611). After six interviews, a preliminary analysis of the data was conducted to look for emerging themes as well as the variables of interest. This preliminary analysis confirmed the structure and flow of the interview guide for the remaining interviews, and helped the researcher to more tightly focus prompt questions and examine some areas in greater depth.

After twelve interviews, saturation was achieved in regards to several key areas of the interview guide. Not only were new materials discussed less and less as each successive interview was added to the study, but after a point the interviews became predictable. These are both indicators that the point of saturation had been reached (Morgan, personal communication).

\section{Participants}

The population of interest for this research was graduate students at Portland State University. The participants all came from departments within the College of Liberal Arts and Sciences, though the focus was not on a particular program or programs. The Sociology department was excluded for ethical reasons as this was the researcher's home department. The students all came from terminal masters programs - ones that offered master's of arts and/or master's of science degrees, but not Ph.D.s. Terminal masters programs are generally found in colleges of liberal arts (Guevara, 2006). These graduate programs share the similarity that they do not have a specific 
professional focus, such as Urban Planning, or produce additional professional credentialing such as business MBA's or Graduate School of Education's teacher certification programs.

Second year students were recruited for this study, based on the assumption that they have had time to adjust to their new graduate student role. The logic underlying the choice of this population is that these students would be more likely to be able to reflect back on what they have learned at college, as well as being able to look forward and share some expectations for their futures.

\section{Participant Recruitment}

Participants were recruited using a number of approaches. The researcher posted a message on the Portland State University campus email message board twice asking for participants who fit the criteria. Emails were sent to graduate advisors, department secretaries, and professors in twenty departments that have terminal master's programs in the College of Liberal Arts and Science requesting that they forward information regarding the study to appropriate graduate students. In cases where departments and advisors made graduate students' email addresses available in response to the request, the researcher directly contacted these students requesting participation. The researcher also contacted faculty in departments that support a number of graduate students and asked for their help in identifying students who were appropriate for this study.

Unfortunately, the recruitment of participants was more difficult than 
anticipated. Recruitment began in January 2008 and was not completed until May 2008. One issue had to with identifying students who fit all the criteria for participation. Individuals who fit one criteria for participating in this research - i.e. being second year graduate students in terminal masters' programs - failed to meet other key criterion. For example, many of the students responding to campus-wide recruitment announcements often turned out to not be enrolled in programs within of the College of Liberal Arts and Science. Other willing potential participants were eliminated from the study because they had already earned one master's degree and were working towards a second. The adjustment and student identity issues faced by current graduate students who had already completed one master's degree were projected to be fundamentally different than the issues facing students working towards their first master's degree. A second recruitment issue had to do with difficulties in securing the cooperation of key gatekeepers who controlled access to potential study participants. While it was not difficult to identify gate keepers, in this case graduate student advisers, to groups of appropriate research participants, it was much more difficult to encourage their facilitation of recruitment for this project. It was only when the researcher began to explicitly invoke the names of the professors from her home department who encouraged contact with specific gate keepers (i.e. "Dr. Bob Liebman suggested that I contact you."), that these gate keepers began to more consistently forward her recruitment messages on to students. 


\section{Data collection methods}

Interviews

Personal interviews, with a narrative approach, were used to explore the experience of graduate education (see Appendix I: Interview Guide and Appendix II:

Graphs). The narrative approach was used to allow interviewees opportunities to chronologically talk through events during their experience at Portland State University using a graph as a visual aid in their construction of their story. This approach also allowed for emergence of connections between interviewees' understandings the graduate student role in their second year versus earlier in their education. Each interview lasted between 40 minutes and one hour and fifteen minutes. The interviews were conducted on the Portland State University campus in a small classroom in the Sociology Department or in the researchers' office.

The participants filled out a short survey for demographic purposes (see Appendix III: Survey) at the start of the interview. This survey allowed for the collection of basic information (e.g. parent's educational level) and verification of the participants' educational timeline in a fast and effective manner. The survey also allowed the participant to self-identify gender and race, therefore minimizing researcher error.

\section{Process of data collection}

Data was gathered using a digital voice recorder and was personally transcribed by the researcher. While interviewing, notes of particular interesting 
comments or observations were kept and were used in conjunction with the transcription. Data on basic demographic information was collected by means of a short survey completed by participants prior to the interview (see Appendix III: Survey).

\section{Interview Tool}

The researcher designed the interview guide with guidance from her committee members. While the interview was completed at a single point in time, the sequencing of questions contained a temporal element, asking participants to report on educational experiences starting back as far as high school, and then progressively moving forward to the present. The first set of questions focused on the participant's high school and college undergraduate experiences. These questions were intended to make the participant comfortable, but also to gauge their intentions towards an advanced degree at different points of time.

The next set of questions asked participants to recall their experiences in applying to a master's program. These questions included: "Why did you decide to apply to PSU?" and "How did you choose which program to accept (if accepted to more than one program)?" These questions were intended to move the participant towards greater self-reflection as well as rooting them in the thought processes and emotions that came up when they were planning a major transition.

The third section of questions asked students to focus on the first few days when they started their master's program: "Let's focus for a minute of what it was like 
when you started your program. Can you tell me about those first few days..." The purpose of these questions was to get participants to recall the feelings and emotions as well as the experiences of that time. Additional probes explored students' perceptions of professors' expectations, peer relationships and other support. This section of questions ended by asking students to compare their experiences during the first few days in the master's program with those closer to the end of their first term of graduate school.

The fourth section of questions that asked participants to use three different sets of matrices to locate themselves in regards to three specific graduate school issues - self efficacy, connection and legitimacy at seven different points in time (see appendix II: Graphs). The first set of matrices was to be used by the participant to describe her relative level of self-efficacy -- how confident she felt about her ability to complete in her master's program. The second set of matrices was to be used by the participant to describe feelings of connection to her department over time and the third set of matrices was used to describe feelings of legitimacy as a graduate student over time. The meanings of these terms was left open for the participant to self-define. The $\mathrm{X}$-access captured "strength of evaluation," in regards to six measurement points: very positive, positive, slightly positive, slightly negative, negative, and very negative. The relationships among these points were maintained, even when the wording of specific questions were slightly modified (e.g. "very positive - very negative" captured the same relationship as "very confident - very unsure", "very connected - very unattached," and "definitely should be here - definitely should not be here"). The Y- 
access captured "time points during grad school." The Y-axis scale had seven time measurement points: "Beginning of $1^{\text {st }}$ Quarter," "End of $1^{\text {st }}$ Quarter," "End of $2^{\text {nd }}$ Quarter," "End of $3^{\text {rd }}$ Quarter," "Mid Summer," "Beginning of $2^{\text {nd }}$ Year," and "Now." By evaluating his or her relative level of self-efficacy, connection and legitimacy in regards to each the seven measurement points on the $\mathrm{Y}$-axis, a participant created a set of three graphs that captured his or her progress through graduate school in terms of these three key dimensions.

Note that the graphs are presented as a way of illustrating how students understood their graduate school experiences over time. There is no assumption of quantitative validity in these graphs. They are not intended to show anything more then trends in students' narratives. As students told their stories, they were asked to chart their relative confidence levels in completing their programs, their feelings of connection to their departments, and their feelings of legitimacy during various times in their programs. While the primary goal of these graphs was to assist in story-telling, they are also valuable in illustrating the positive or negative trends in the participants' narratives.

The fifth section of questions asked participants to reflect on how their experiences in transitioning to graduate school might compare to the experiences of other students in their own program. Then participants were asked to explain their perception of the value of their chosen educational path (e.g. "How do you think the path that you took helped you?" "How do you think the path that you took hindered you?") 
The purpose of the final section of questions was to wrap up the interview. One question asked participants to project how their educational path and graduate school experiences would impact their occupational and lifestyle options in the future. The last question encouraged participants to reflect upon and make explicit the lessons learned in graduate school by asking what advice they would give themselves if they could go back in time to when they were beginning their respective master's programs.

\section{Confidentiality}

While the participants in this study did not comprise a high risk category, there was concern over confidentiality. One participant specifically asked twice during the interview for reassurance that individuals would not be identifiable in the final report. This concern came from the personal nature of some of the stories and the potential for repercussions from faculty members involved. The informed consent form was reviewed before each of the interviews; it included the contact information on the principal investigators, the purpose of the study, how the interview data was going to be used, procedures for maintaining confidentiality, and HSRRC contact information. Voluntary participation was stressed, as was the right to not answer a question if it was too uncomfortable. Excerpts from the interview transcripts have been used throughout this thesis, but all names and identifiable information has been changed. As there were two males of the same age in the traditional / linear trajectory group, all of the participants were assigned a participant identification code. These codes are to help 
with clarity in the results and discussion chapters, as well as protect the participants' privacy.

Table 1

Table 2

\begin{tabular}{|c|c|c|}
\hline \multicolumn{3}{|c|}{ Traditional / Linear Trajectory (TLT) Participants } \\
\hline Gender & Age & Participant ID \\
\hline Female & 25 & TLT-1 \\
\hline Female & 26 & TLT-2 \\
\hline Female & 23 & TLT-3 \\
\hline Male & 25 & TLT-4 \\
\hline Male & 25 & TLT-5 \\
\hline Male & 24 & TLT-6 \\
\hline
\end{tabular}

\begin{tabular}{|c|c|c|}
\hline \multicolumn{3}{|c|}{ Non-Traditional / Broken Trajectory (NTBT) Participants } \\
\hline Gender & Age & Participant ID \\
\hline Female & 32 & NTBT-1 \\
\hline Female & 42 & NTBT-2 \\
\hline Female & 27 & NTBT-3 \\
\hline Female & 36 & NTBT-4 \\
\hline Female & 29 & NTBT-5 \\
\hline Male & 35 & NTBT-6 \\
\hline
\end{tabular}

\section{Potential for Bias}

Researcher biases and strengths

As a returning student herself, the researcher's own experiences informed this study. The researcher returned to college to earn her master's degree almost 13 years after completing her bachelor's degree. The researcher hoped that similarity to the returning students that were interviewed would engender trust to explore and express their experiences without worrying about an "outsider's" perception of them.

This same connection was not present in regards to students who were on a traditional / linear educational path. However there was still a strong connection 
between the researcher and traditional students in she was also a master's level student going through many of the same situations that they were encountering. The experiential differences between the researcher and these participants were explored during the interview in the same way that the experiential similarities with the returning students were.

The potential for bias here is no greater than that which is present in all qualitative research. As Freeman (2007: 27) notes:
"Qualitative data and information are always already interpretations made by participants as they answer questions or by researchers as they write up their observations. Neither research participants nor researchers can be neutral, because... they are always positioned culturally, historically, and theoretically."

From this perspective, the researcher's bias towards understanding the challenges faced by returning students in a more holistic sense must be recognized. One means of limiting potential bias was the use of "member checks" (Lincoln and Guba, 1985), a technique where the researcher offered each participant the opportunity to read over her transcript. At that point the participant could offer clarifications to any area that she believed was ambiguous or erroneous. Of the participants, two took the advantage of the opportunity to read the interview transcript, but after doing so neither felt that there was any need for clarification of her responses. Two other participants declined the opportunity to read the transcript but invited the researcher to contact them if there was a need for response clarification or additional questions. The remaining 
participants all declined the invitation to read the transcripts.

An area of challenge was for the researcher to decide how to present herself. As Fontana and Frey point out: “...telling a respondent that "I am a mother of three" versus telling the respondent that "I am a university professor" accesses different categories and elicits different accounts" (in Denzen and Lincoln, 2005: 719). The researcher began with the belief that presenting herself as a graduate student might produce feelings of sympathy from gatekeepers and, therefore, cause them to be more likely to help her gain access to the potential study participants. Ultimately, what was needed was a "differentiated" self-presentation. When contacting gatekeepers, a selfpresentation of "researcher" was used to elicit assistance in the recruitment of subjects, but when contacting potential participants a self-presentation of "master's level graduate student doing research for her thesis" was used to encourage students to take part in the study.

\section{Method of Analysis}

Each of the interviews was personally transcribed by the researcher and read in entirety twice before any analysis was begun. The content of the interviews was explored through qualitative thematic content analysis as well as through a narrative lens.

Thematic content analysis

Simons, Lathlean and Squire describe thematic content analysis as the "search 
for themes across the data set on the basis of content" (Simons et al., 2008, p 123). In this study, this approach took the form of three separate rounds of coding the data. In the first round, basic codes were developed tied to general conceptualizations or descriptive terms such as "faculty support" or "support from others." These terms were emergent and the language of the participants were used as often as possible. The second round was directed at developing more specific codes that reflected the research questions, such as "belief in ability to complete the program." In the final round of coding, the categories identified in the first two rounds were standardized and then applied to all the transcripts. Consistent with the research design, the thematic content analysis used the coded data to identify themes within each of the two groups participants and as well as similarities and differences in themes between the groups.

\section{Narrative Analysis}

Dey describes narrative analysis as:

"the focus on process, both its temporality in terms of stages and sequences of events and its evolution through conditions, interaction, and consequences...(actors) categorize phenomena not just in terms of representing objects or events, but also their relationships within an overall configuration which makes sense (more or less) of experience" (in Bryant and Charmaz; 2007: 184-185)

Using narrative analysis, the researcher examined the form of each participant's account, looking to see if the story was told in an active or a passive voice, and if the 
story line was stable (i.e. did not change over time), regressive (i.e. story became more negative over time) or progressive (i.e. story became more positive over time) (Gergen and Gergen, 1988). “...Narratives can be compared and combined. While not designed to be a precise mathematical instrument, story lines can also reveal perceived peaks and valleys in people's lives, and their relative impact on the narrator... Story lines are also useful for conducting dialogues with narrators about their lives" (Gergen, in Antaki, $\mathrm{p} \mathrm{111).} \mathrm{The} \mathrm{narratives,} \mathrm{including} \mathrm{the} \mathrm{physical} \mathrm{graphs} \mathrm{that} \mathrm{the} \mathrm{participants}$ created, were examined to determine the narrative form of the story line. Using the self-efficacy, connection and legitimacy graphs was helpful in identifying the common types of graduate student narratives. As explained by Gergen:

"The protocols designed with the story line method proved to be very useful in summarizing the feelings of the sample over time...Given that the number of respondents was small, the major attempt was to assess what types of narrative form seemed most common to people in the study" (in Antaki, 1988: 103-105).

Using two analytic approaches to examine the same data added richness to this study. It was not counter-intuitive, nor did it cloud the results. As Simons noted in his discussion of the value of using a similar approach to analyzing qualitative data: "it was about shifting the focus - viewing the same object from the same standpoint but adjusting the lens to bring into view particular aspects of the phenomenon, one after another" (Simons et al, 2008: 129).

This chapter presented the methodology used in this research. It provided an 
overview of the research setting, the participant characteristics, and the design of the project and the interview. Confidentiality and researcher bias were addressed. The chapter concluded with a description of the method of analysis. The next chapter will address the findings of the research. 


\section{CHAPTER 4: Results}

The results in this chapter are organized by four major sections. The first section is "themes within the traditional / linear trajectory group" while the second section is "themes within the non-traditional / broken trajectory group." The third section focuses on "between group similarities in themes" and the last section presents "between group differences in themes."

The first two sections, which focus on understanding the experiences of the two groups of students making the transition to master's programs, share four themes. The first common theme is "support" and includes relationships with peers, faculty relations, academic advising and other support. The second theme is "confidence in completing the program," which includes both feelings of competency and fears. The third common theme is "feelings of connection to the department," which includes both academic and social connections to the department. The fourth and final theme is "feelings of legitimacy," basically does the individual feel validated as a graduate student? This organization helps to answer three of the four original research questions. The original research design was devised so that these three questions would shed light on the fourth research question regarding how the students understand the role of graduate student. Therefore, that question will be addressed in the discussion chapter. 


\section{Themes within the traditional / linear trajectory group}

\section{Support}

\section{Relationships with Peers}

With regard to their relationships to other students in their master's programs, the majority of the traditional / linear trajectory students viewed their peers as being in the "same position" as themselves. Even if they had doubts about how well they "matched up" with other new students in the beginning of their programs, over time traditional / linear trajectory students came to see other graduate students as 'just normal people' like themselves. They believed that all students have some conflicting feelings towards graduate school: "I think something that would be characteristic would be doubt and confidence simultaneously" (male, 25: TLT-4). Another student explained this commonality:

“After talking to (other) people (in my program), I confirmed that initial assumption that everyone was feeling the same sort of anxiety. It seemed pretty much true that everyone was feeling "what am I doing here? Do I really deserve to be here? Can I do this?" (male, 25: TLT-5)

Of the six students in the traditional/linear trajectory group, there were two who had a more negative view of their peers. One claimed that she was uncomfortable with the amount of competition in her department, but that competition was necessary in graduate school:

"I have been told from other people that it (the department encouraging competition) is intentional because the real world is very competitive for 
jobs and for recognition. You have to be competitive. I don't want to hate them (other students)... even now it is hard for me to sometimes (not to be competitive). In chatting in class: 'How are you doing on your paper?' 'Well, I finished it last night and now I am...' and I am thinking 'shit, she is done. I need to do better than she did.' I really hate those feelings and thoughts. I try to disconnect myself from it, because it really makes your friendships twisted." (female, 23: TLT-3)

The other participant with a negative view of peers felt that those students were better prepared for graduate school both academically, financially and socially: "I feel like people in my department / (program) had come from very privileged backgrounds and they either had a spouse or (some) other way to support themselves or had really strong academic backgrounds to prepare them for this... I didn't feel like I really fit in..." (female, 25: TLT-1)

Faculty relations

Relationships with key professors, such as department chairs and committee chairs, were seen as important relationships to the majority of the traditional students. All six of the traditional / linear trajectory students told stories of how a faculty member made a positive impact on the student's graduate school experiences. The nature of the relationship might be slightly different from case to case, but the effect 
was always one of feeling supported. Several described supportive relationships with department chairs. One noted:

"(It is) a formal relationship, but its good because he is really helpful. He knows the system really well and can encourage me and say that 'you don't need to worry about this yet, just focus on this stuff.' That is definitely very helpful for keeping that confidence level up..." (male, 25: TLT-5)

Other students felt that it was their advisors and professors who provided more direct support for them. One student, who was considering leaving the program because she felt that some of her professors, including her thesis chair, questioned whether she belonged in the program, told this story:

"One day I pretty much started crying in my (thesis chair) / adviser's office and he is a very stern, old school, traditional adviser. But I think when I started to cry, he got the picture. And he was like... he said flat out that 'if you shouldn't be here, I would tell you. You would know if you didn't deserve to be here. You would know.'... that felt... I felt much reassured." (female, 23: TLT-3)

She went on to say that she believed that the difficult relationship that she had with her thesis chair was some kind of "rite of passage" that, once she got through it, she felt like she was a better student. She claims that she now has a very positive relationship with that professor, where they can talk about academic matters as well as "joke around." 
There was one traditional / linear trajectory students who, while

acknowledging that he had positive interactions with professors, did not see professors as important sources of support. He explained it this way:

“(When I complete this program) I think the fact that I have a master's degree will be of huge benefit, but I think my previous work experience (during the summer and school year) will count more than having a letter of recommendation from a professor." (male, 24: TLT-6)

This same student had limited meetings with his committee chair and, when interviewed, was still unclear on how many thesis committee members he needed. Compared to some other students in his group, he seemed to have a limited idea of how a positive relationship with a professor could help him; his ideas about "support" seemed to begin and end with a letter of recommendation for employment. He used other students as his primary support with the graduate program.

\section{Academic advising}

Most of the traditional / linear trajectory students did not have positive stories to tell about department advising support for master's students. None of them claimed to remember participating in a department orientation. Four of the students told stories of academic advisers that were unavailable in some way. One of the advisers made the student feel unwelcome:

"I set up one meeting with her and she acted so irritated that I was wasting her time, her five minutes...she was so overwhelmed with work 
that she couldn't help me with even answering questions about what I needed for graduating." (female, 25: TLT-1)

The second student had an adviser who was physically not available:

"I was assigned to an academic adviser who then immediately went on sabbatical. So basically what you see on the website is what you get in terms of course planning" (male, 24: TLT-6)

Another student explained how his adviser did not show up to their first, and only, meeting:

"I tried to contact the graduate adviser. I finally ended up getting in contact with him and setting up a meeting to talk about classes and what I should take and if there are some requirements... and I showed up and he wasn't in his office. I left him a note and never ended up seeing him at all. It was not helpful. This was before classes actually started so I just signed up for classes that looked good." (male, 25: TLT-4)

The fourth student had a similar experience with the adviser not showing up:

"I had a meeting with my adviser the week before classes and he forgot that we had a meeting and I was sitting in the department for like two hours and he wasn't there and it's just like that." (female, 23: TLT-3)

\section{Other Support}

All of the traditional / linear trajectory students felt very supported by their social networks out-side of school. They all had at least one external source of 
emotional or social support: "I had one person (my husband) that never wavered and never questioned and was always confident in my ability to do it..." (female, 26: TLT2). Two cited financial support as well as emotional support from parents as important factors in their decision to attend school:

"My parents are the ones that really pushed it early on. After I had my bachelors, they were like 'Keep going. We still have some money left and we are willing to help, so keep going." (male, 25: TLT-5)

Unfortunately, family support was not an "all or nothing" experience. For example, one student (cited above) expressed strong support from her husband, but stated that her parents "thought that going to college was something for me to do until I got married... they (say they) are supportive, but they don't understand what I am doing" (female, 26: TLT-2). Interestingly, she was the only one of the traditional / linear trajectory students who did not feel that she had complete support from her parents, and was the only traditional / linear trajectory student who was married.

\section{Confidence about Completing Program}

Overall, traditional / linear trajectory students' views of their graduate school experiences followed a progressive path as their views became increasingly positive over their time in their master's programs. Their relative levels of confidence in their ability to complete those programs also increased over the same time. 
Figure 4

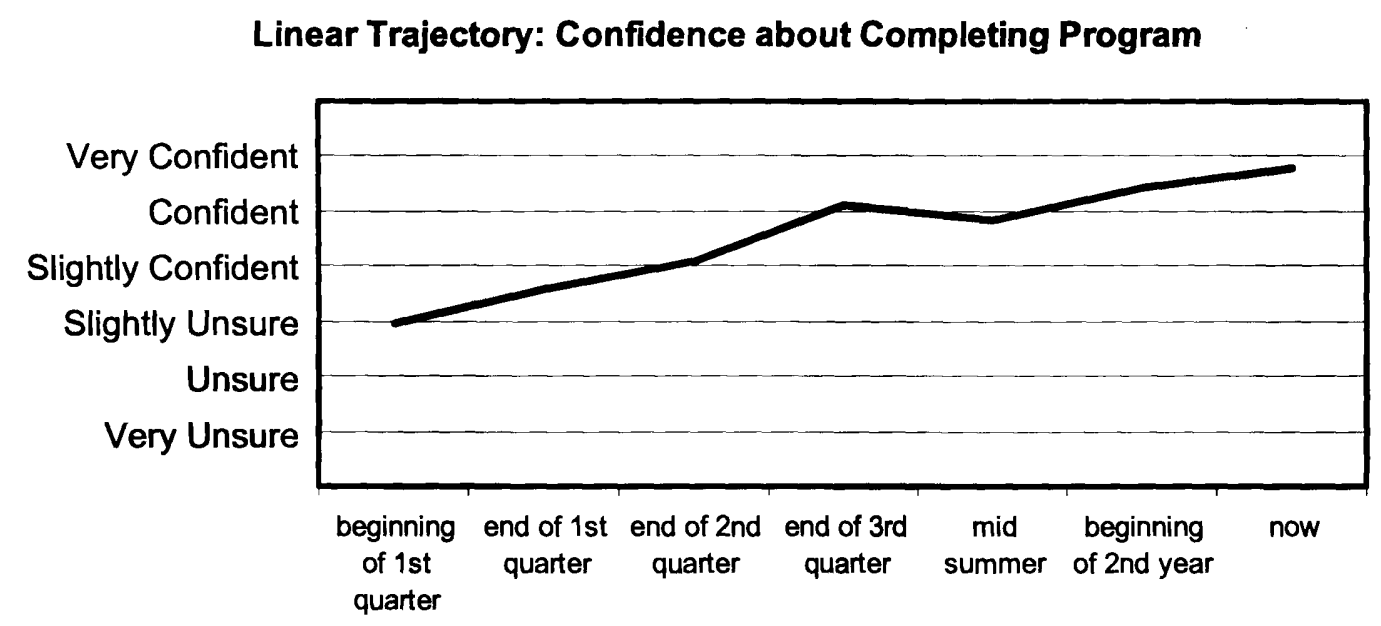

As they told their stories, each of the students was asked to chart her or his confidence level at the different times in the master's program. The graph shows a "progressive" pattern - i.e. that there was a positive growth in confidence between the times that students began their first quarter in their graduate programs and when the interviews took place ('now'). The slight dip in confidence about completing the program during the summer was interesting. Students generally explained this dip as a result of not getting as much done during that time as they expected and the diminished contact with people in the program during the break.

When asked about relative levels of confidence over time, one traditional / linear trajectory student explained:

"That first term I felt like I was still an undergrad, I hadn't pushed through... after that I figured out that I was not just here to go through the motions, I had to figure out where I was going." (female, 25: TLT-1) 
Based on doing well in classes, talking to other graduate students, and comparing themselves with undergraduate students in some courses, master's program students' confidence began to increase:

"I can see how far I've come because I can look at an undergrad and say 'yes, this is where I was at, and now I am here' so I can see the progress that I have made." (male, 25: TLT-5)

Fears

The fears that traditional students admitted to having were often linked to external factors, such as attending to the details of university paperwork and the ability to afford their education. As one participant observed:

"it's more just the feeling that there are all of these other little things that could pop up and undermine what you are doing. So you know you can have a 4.0 but if you don't get this form in on time you are screwed" (male, 25: TLT-4).

\section{Feelings of Connection to Department}

Similar to the progressive development pattern found in reports of levels of confidence in completing their programs overtime, traditional / linear trajectory students reported that their feelings of connection to their department also increased over their two years of graduate school. Students understood connection to the 
department as involving both academic and social connection with other students and with faculty.

Figure 5

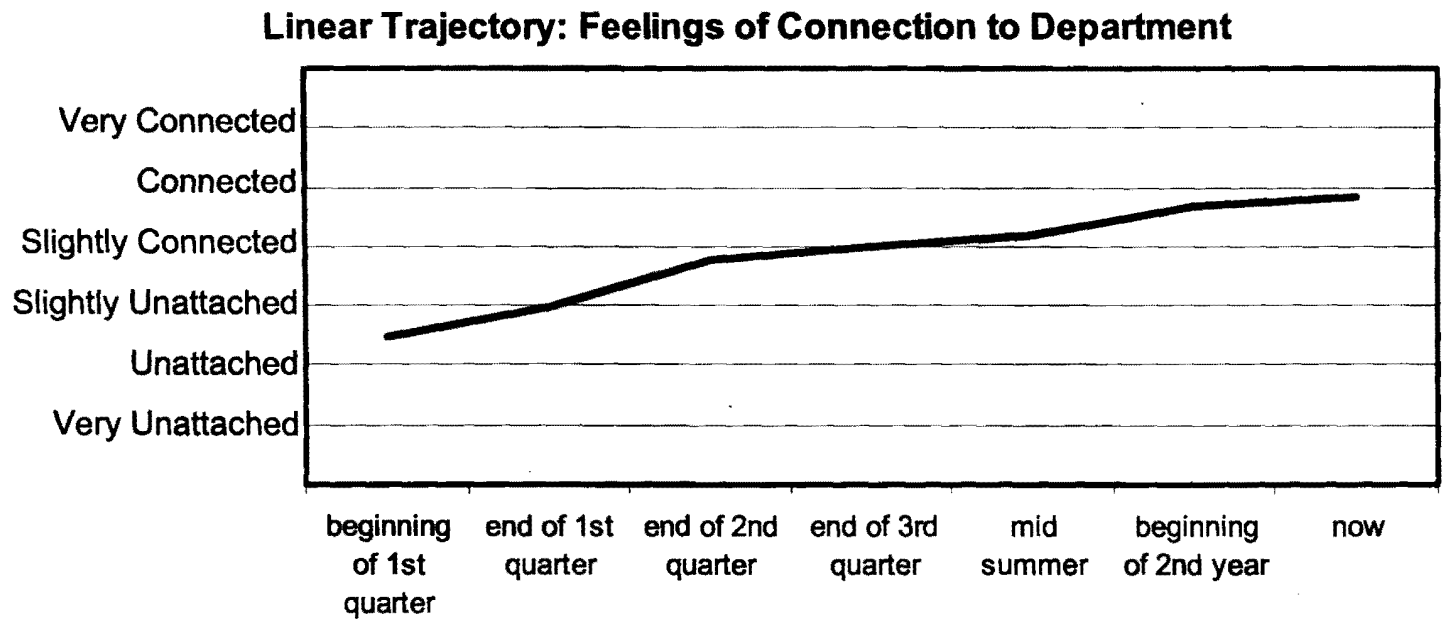

In the beginning of their program, the traditional / linear trajectory students reported that they had mixed emotions about their feelings of connection to their programs. As one student noted:

"I guess I can say that I felt connected at some level but at other ways not very connected. Which is partly my personality, I guess... in a way I felt connected in that I felt that this is where I should be and I got along with everybody but then I was not very outgoing so the idea of a big meeting... I would rather go hungry and eat on my own" (male, 25: TLT-4)

Three of these students specifically split their feeling of connection into a social and an academic component. The academic connection had to do with their 
ability to do the graduate-level work. The social component referred to building a relationship with peers and faculty in the department:

"(Did I feel connected to the department) in terms of the material and the academics? Absolutely. It's what I like to do. Stuff that I've covered before, its just like going in at a deeper level. In terms of socially, no. But I think it goes back to that we had a small class and we all had jobs so there was not true social interaction. You talked for five minutes before class, talked for a moment after class then you go home" (male, 24: TLT-6)

Some of the students felt that they were ready for the academic portion, but the social portion with peers was more difficult. As one stated: "there is always that initial stage where you are trying to get a read on someone, 'is this someone I can work with? How is this person going to be useful to me?" (male, 25: TLT-5)

One of the traditional / linear trajectory students did not experience the increase in feelings of connection over time, but reported relatively low feelings of connection throughout her time in her program. She lacked feelings of both social and academic connection with her peers, faculty and department. In the beginning, she felt that she did not fit in with her peers, that they had come from "privileged backgrounds" and were more prepared for school than she was:

"I didn't feel like I really fit in... In class people were quoting Latin scholars and other literatures and spoke five languages fluently and had lived in all of these places around the world and had all of these amazing 
life experiences and I definitely felt wow... it was hard for my self esteem, definitely. I was hard to be in those situations and really question if I was worthy to be there so that took a few months... definitely." (female, 25: TLT-1)

As she progressed through her graduate school timeline, her disconnect focused more and more on the department and faculty rather than her peers: "They would not even respond to my emails sometimes. And it is such a small department it would not be hard for them to do some of these small things." When discussing her committee, this student responded that there was nothing that they could have done to make her feel more connected because by that point, "it was too late."

\section{Feelings of Legitimacy}

Similar to the patterns seen for changes in confidence about completing programs, and connection to programs over time, the traditional / linear trajectory students' feelings of legitimacy as graduate students also followed a progressive path and increased over their time in their master's programs. They all reported experiencing episodes of questioning their own legitimacy as graduates in the beginning of their programs, especially in regards to their academic ability, but for some students this was a much greater issue than for others. Three students expressed feelings of initially being nervous, but that it passed fairly quickly:

"(I was) obviously being nervous about what the classes were going to be like: were they going to be way different? Way more advanced? Or more of a 
continuation? By the time I actually got into class it seemed pretty natural... no big events that actually stand out, but it felt like it was what I should be doing and that I fit in and things like that" (Traditional / linear trajectory, male, 25: TLT-4)

Figure 6

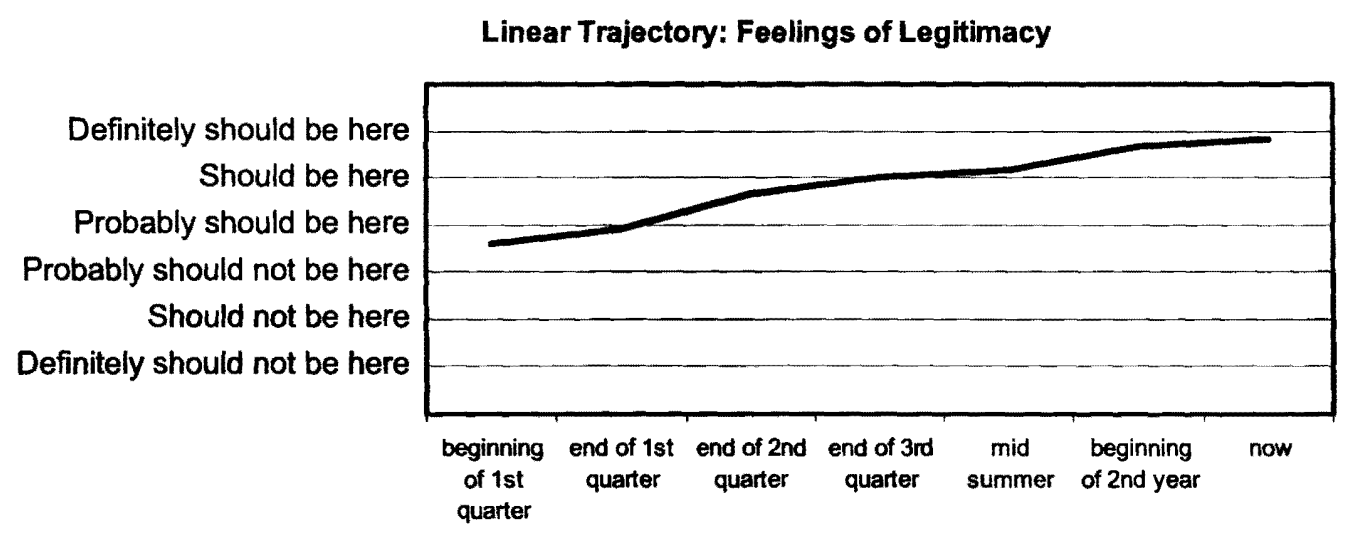

The other three traditional / linear trajectory students experienced a significant crisis in their respective senses of legitimacy at the start of their master's program. One of the students linked her issues of questioning of her legitimacy as a master's student to her gender: "I grew up in a place where that (getting a degree) wasn't what most people did, and it definitely was not something that women did." (female, 26: TLT-2). This student later went on to explain:

"I was just questioning my life choices, especially compared to what had always been expected of me growing up. Despite how you try to change that, you still have something in the back of your head saying 'Why don't you have any children? You are supposed to have four by now!" 
The other two traditional / linear trajectory students who had crisis in their sense of legitimacy questioned it more directly:

"(My sense of legitimacy) is fluctuating all the time... Sometimes I feel like I shouldn't be here at all. Other times I feel like I should walk out with my master's today. I am definitely ten times as emotional as I ever have been in my whole life since I've been in graduate school. Everything is intensified." (female, 23: TLT-3) 


\section{Themes within the broken trajectory group}

\section{Support}

Relationships with Peers:

Relationships with peers were important to the broken trajectory group. They were a source of concern in the beginning of the program for three of the students who worried that they were not as prepared as the other students:

"I was sure that everyone else was brighter, had more experience... I had a couple of second year graduate students in one of my classes and I thought 'I am never going to sound like that. They really know what they are talking about."' (female, 32: NTBT-1)

Those three students also expressed being impressed with the quality of the other students: "I was very impressed by the caliber, the educational background, and the experience of the people that I met and continued to meet" (female, 42: NTBT-2)

Five of the six broken trajectory students also expressed confusion or irritation with students who did not live up to their expectations. One student expressed his frustration this way:

"It just blows my mind that there are people who are in a graduate program that don't really know what they are studying, that don't really push themselves, that don't really get involved with as much as they possibly could. It just boggles my mind... I can't understand why people would do that." (male, 35: NTBT-6)

A similar sentiment was expressed by another of the broken trajectory students: 
“First of all I don't know why anyone would pursue an advanced degree and pay all this extra money to not be serious and to kind of look at things like a joke, or not come prepared and not have done the reading, not to understand the reading and not to work on writing well..." (female, 27: NTBT-3)

\section{Faculty relations}

Five of the broken trajectory students used the word "peer" to describe either what their professors wanted from them or their perception of their relationships with their professors:

"I knew that right from the bat they expected excellent writing, well put together research papers organization-wise, participation, thoughtful indepth comments in class, basically to interact like a colleague, like a peer, because you are a graduate student now and they are setting you up to enter this field and you may eventually be one of their colleagues one day, and so they are treating you like one." (female, 27: NTBT-3)

The three that used "peer" to describe what they felt that their professors expected from them also expressed concern about being able to live up to that standard at some point during the interview. As one stated:

"The hardest part I thought was going to be living up to the professors' expectations. I felt like they had given me this opportunity to be here and that they would regret letting me in." (female, 32: NTBT-1) 
The one student that did not use the word "peer" explained that she had a good relationship with the faculty, especially her adviser. While she saw this adviser as a great "resource," she also was not clear on the expectations of the relationship:

"I was assigned an adviser at the very beginning. I didn't even know that we could change... that could be a little awkward... can we change?" (female, 42: NTBT-2)

This student had been out of school longer than any other broken-path student and was the only one that had not been working for pay during her break. As she had not had to navigate hierarchical relationships in the working world, this may explain why she deviated from the other five in this area.

Academic advising

None of the broken trajectory students remembered a department orientation beyond a gathering where everyone stood-up and introduced themselves. This was frustrating to some of the students:

"That was really horrible for me. I went in there several times and was like, 'Is there any sort of orientation?' or 'Am I doing the right thing? I haven't heard from you' and they were kind of like 'Oh, no, you're doing the right thing. Orientation? I'm not really sure.' ...I guess maybe I was expecting there to be something a little bit more before school started, which would have made me feel a little bit better. Maybe I'm just being an overachiever or something. There was one, like, mingling 
type of thing that was pretty good, but I remember being really frustrated before school started because I wanted more contact from them regarding what was going to happen...So yeah, there was, but I didn't really feel like there was really enough of one." (female, 29: NTBT-5)

One of the students did talk about seeking out other opportunities, such as a graduate student orientation that he believed was put on by Student Affairs, but it was not an orientation for his department:

"there was a graduate assistant presentation that was given at the very beginning of the year, given by the Student Affairs folks, it was a day long intensive kind of intro to the whole thing and they ran down the basic scenario for what its like being a grad student. It was mostly directed towards being a teaching assistant so it wasn't all applicable to us, but there were some aspects to it about interfacing with people with developmental disabilities and working with professors when grading papers and that kind of thing so I purposefully sought that out and took advantage of that." (male, 35: NTBT-6)

\section{Other support}

All of the broken trajectory students had significant support from their primary personal relationships, although the character of those relationships differed. For one, who was a single-parent, it was her daughter:

"My daughter is really proud of me, but once... she came up to me and 
said that since I had gone back to school I had been grumpy. So I felt 'I am so sorry, sweetie.' So I thought, I need to rethink this. My daughter, my whole family (her daughter and an international student), we all study at home. She is very encouraging in her own way; she even offered to wash dishes, which she hates, if I needed to study." (female, 42: NTBT-2)

For others this included spouses, parents and friends. There was one student who had significant support in his life, but did not feel that his parents actually understood what he was doing:

"My family doesn't really know what it is like to be in (graduate) school at all and it's hard to explain it to them so they don't really know how to support me. Yeah, they are trying, but..." (male, 35: NTBT-6)

\section{Confidence about Completing Program}

All of the broken-path students felt a very high level of confidence about completing the program throughout. 
Figure 7

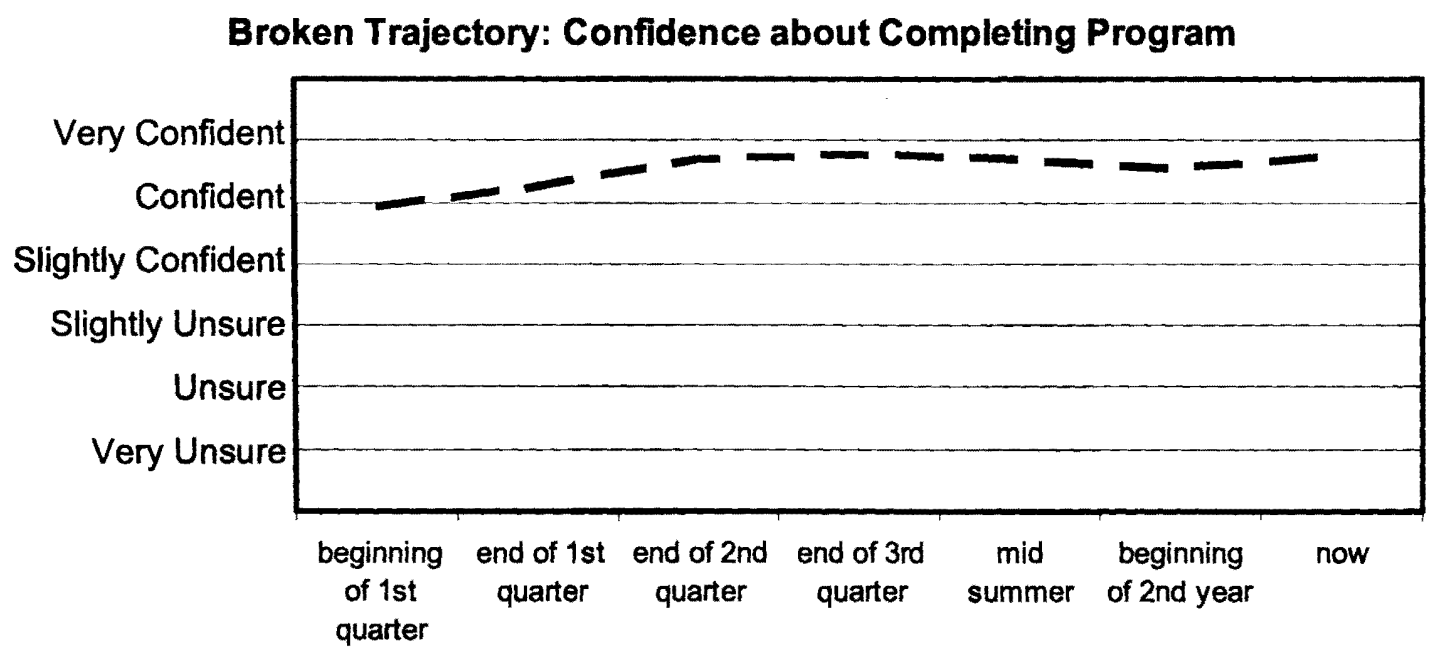

The explanations that were given by five of these students were all very similar. As one student stated: "I would not have started a program if I didn't think I could've completed it" (female, 36: NTBT-4). The one who had a different explanation referred to her religious belief:

"I just always knew, I just always believed that this is what God has called me to at this time, and I just, not that it was easy or that I didn't have questions, I just felt that this is what I am supposed to do. It is just a question about how long it is going to take me." (female, 42: NTBT-2)

These students felt that they had made a conscious decision to attend graduate school and were going to complete it, even if some of them had times of doubt about their capability: "It was only in the very beginning, that first term that I thought that maybe I wasn't cut out for this, but I knew I had to stick it out. It really never crossed my mind to quit." (female, 32: NTBT-1) 
Fears

The fears that the broken path students felt were both external fears, such as knowing what to do in order to graduate and being able to do the thesis, and internal fears such as being able to balance life and school. Three of the participants specifically mentioned the internal issue of worrying about finding balance in their lives the first term of their program:

"I wasn't used to having to be certain places at certain times and I didn't want to neglect my child so I had to rethink my life. I don't want to live in a pig sty and I have to do my yard. I have to balance everything." (female, 42: NTBT-2)

Another of the students expressed his similar concern: "(I expected the hardest part to be) maintaining balance in between work and non-work, between school and out-ofschool life." (male, 35: NTBT-6)

\section{Feelings of Connection to Department}

The broken trajectory students developed increasing feelings of connection to their department over time. 
Figure 8

\section{Broken Trajectory: Feelings of Connection to Department}

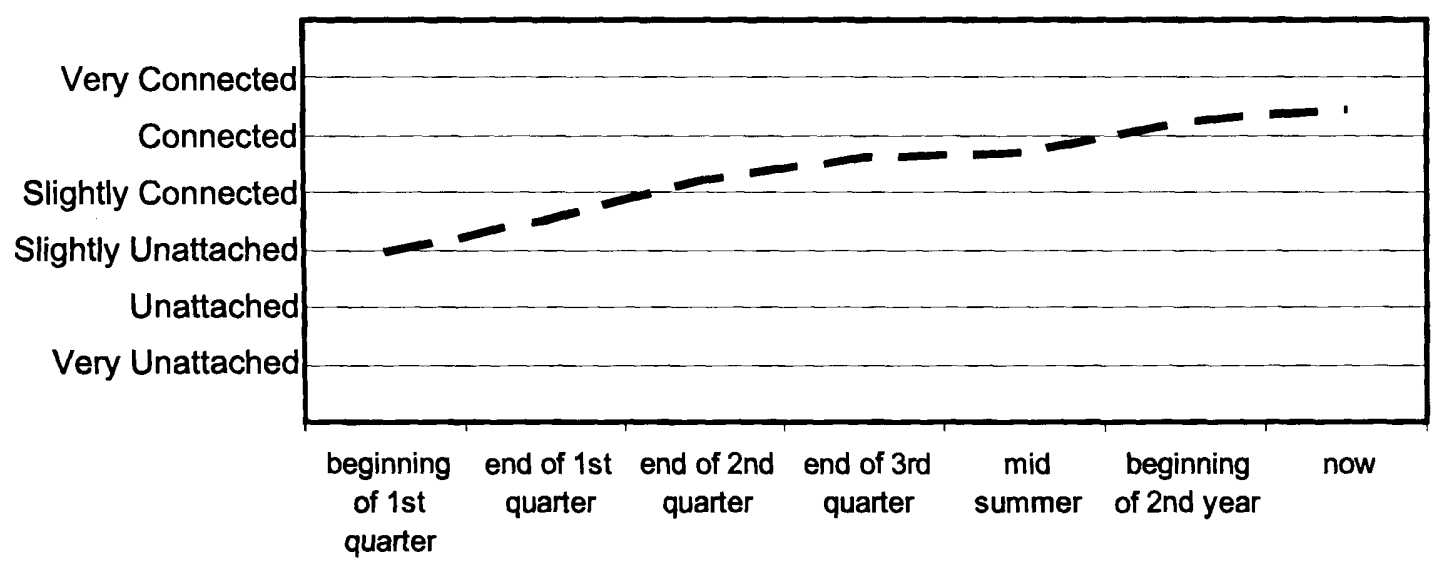

The most common explanation was getting to know people in the department, especially professors:

"I didn't feel connected in the beginning, especially because I didn't have a desk or an office like some of the other students... As I started spending more time with some of the other students, I felt more connected. The professors also began to recognize me... now I feel like I belong. I guess it has just been getting to know people, and not feeling like they don't have any idea who I am." (female, 32: NTBT-1)

Explanations of developing connections were usually couched in active terms - in how the student "pursued" these relationships or "sought" opportunities to feel connected. One student explained it this way: "I think that I have taken the initiative to take part more than I have been asked to take part." (female, 27: NTBT-3) 


\section{Feelings of Legitimacy}

Figure 9

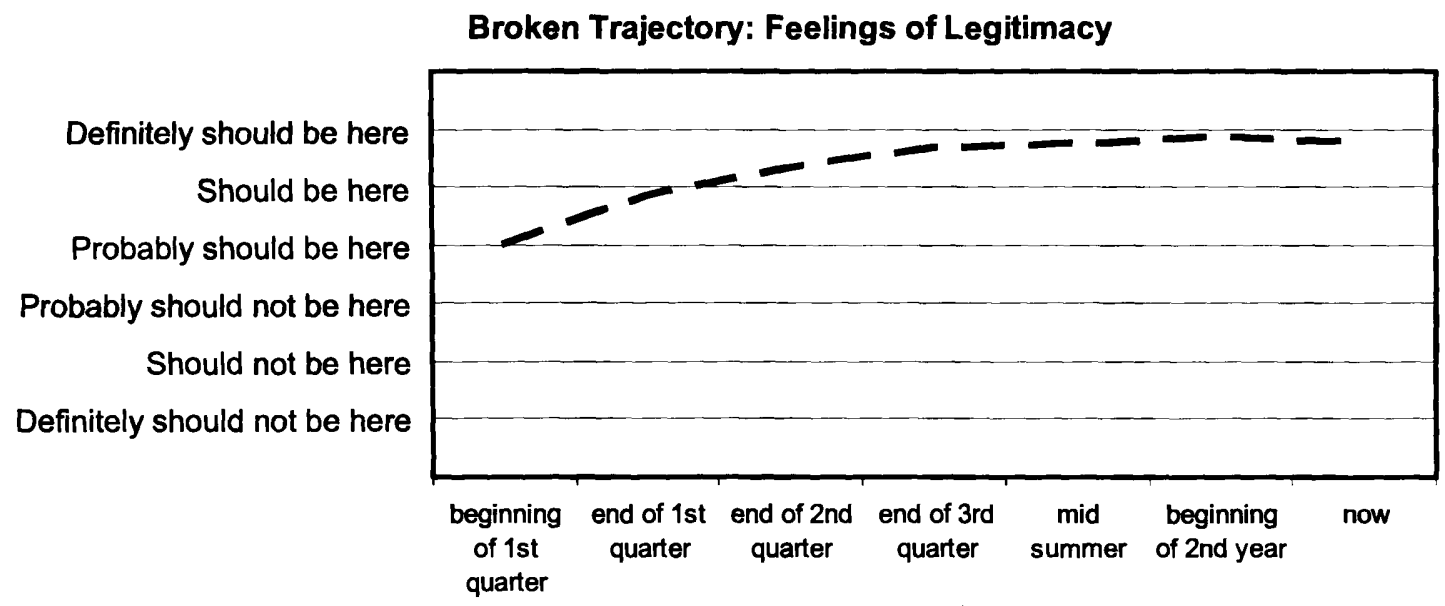

Broken trajectory students appeared to have an internal argument regarding

their feelings of legitimacy. They graphed their feelings positively, but they expressed stronger feelings of doubt, especially during the first term: "I was so in shock in the beginning. I thought 'I can't do this. They are expecting too much and why did I ever get myself into this?" (female, 42: NTBT-2)

This attitude appeared to change, not necessarily because of successes in school, but because of a shift in their attitudes: "I'm working so hard. I see school as my job, and I'm doing a great job because I love what I do" (female, 36: NTBT-4). All six of the broken trajectory students mentioned an increased understanding of why they were in school. As one student noted:

"I love it. Seeing everything I can do with it, that's really exciting to me... my motivation is that I truly look at this as my life's work and a 
career that I wouldn't mind having for the rest of my life" (female, 27: NTBT-3)

Another of the students expressed a similar sentiment this way:

"I came back to the academy and was reminded how much I love the academy and how I probably will be working in the academic setting when I get out of school because I love it so much" (female, 29: NTBT5)

This shift in attitudes may explain the seeming paradox of broken path students being stressed and feeling out of their element in the beginning, yet over time claiming the legitimacy of attending a master's program. 


\section{Similarities between groups}

\section{Support}

Academic advising

Both groups reported not participating in a department graduate student

orientation. For both groups, this was not due to a lack of interest on the students' part, but instead due to the departments not offering such an orientation.

\section{Other support}

Both groups of students felt secure in the support they received from their significant relationships. In addition, both traditional / linear trajectory and broken trajectory students indicated that this outside-of-school-based support was important to them in regards to succeeding in graduate school.

\section{Feelings of Connection to Department}

Figure 10

\section{Feelings of Connection to Department}

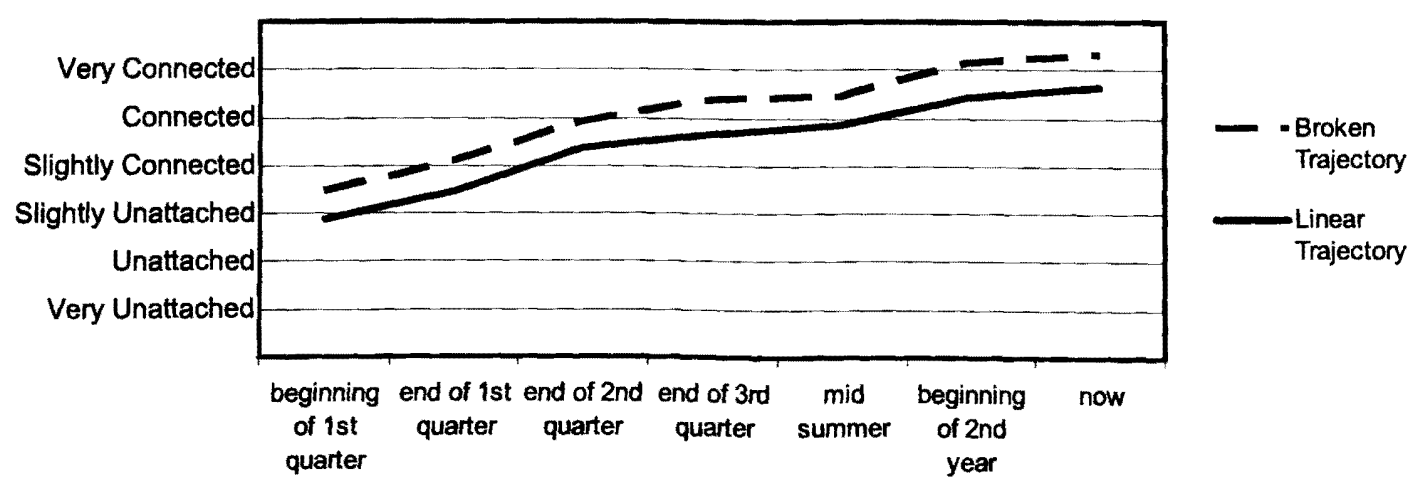


Students in both groups began their respective master's programs with feelings of insecurity about whether they fit in with their departments. All students expressed concern that they did not know their peers or their professors as well as they would have liked to. In addition, both groups of students demonstrated a progressive development pattern in that they reported that their feelings of connection to the department increased during their time in their master's programs. Also both groups attributed these changes in feelings to their getting to know more people within their respective departments.

\section{Differences between groups}

\section{Support}

Relationships with peers

One striking difference between the two groups is what they expected from their peers. The traditional / linear trajectory students' expressed expectations were less intense, and more ambiguous, than the broken trajectory students expectations. The broken trajectory students not only gave a list of expectations for a "typical graduate student," but often expressed confusion and annoyance when the other students did not live up to those expectations. As one broken trajectory student noted:

"I have expectations of them in general that sometimes aren't met. It disappoints me and it really pisses me off... I am just like 'if you are not going to do anything, get out and let someone else take your spot who will.' I have no tolerance for that... or people that you can tell that 
obviously have not prepared. I can cut slack for undergraduates, but for graduates, I don't have any sympathy for that." (broken trajectory, male, 35: NTBT-6)

Interestingly, when each group was asked directly about their perceptions of the other category of students, the traditional / linear trajectory students actually felt that the broken trajectory students were in a better position as students:

"I think that maybe they have it easier. And I feel like they are better students because they are more mature and they know what they are doing a bit more, so, I don't know. I feel like I am having more fun in grad school than they are, because I am not taking it so seriously." (traditional / linear path, female, 25: TLT-1)

The broken trajectory students also seemed to feel that they took school more seriously than some of the traditional / linear trajectory students, but they saw this as a positive: "I also think that since I made a real decision to come back to school, maybe I take it a little more seriously. I am not saying that they don't, but..." (broken trajectory, female, 32: NTBT-1)

\section{Faculty relations}

There also was variation in how the two groups of students understood and perceived professors' expectations. The traditional / linear trajectory students were aware of the expectations of being a good student based on their use of academic 
achievement for judging their legitimacy as graduate students, but most did not report feeling 'performance stress':

"they (professors) realize that chances are that (for) $90 \%$ of the class this is the first graduate class that they have had, so they are pretty lenient and they go over background information at first to jog your memory and that you remember this and that" (traditional / linear path, male, 24: TLT-6)

The broken trajectory students appeared less aware of these expectations. As one broken trajectory student pointed out:

"the professors seemed to expect a lot from all of us. They really expected quality writing. I had been out of school for a while, so I felt really behind everyone else and was afraid that they professors would think so too." (broken trajectory, female, 32: NTBT-1)

Another difference was the perception by some students that faculty were preparing graduate students to be their academic 'peers.' Whereas five of the broken trajectory students mentioned some faculty expectation about graduate students being, or becoming, 'peers,' none of the traditional / linear trajectory students made mention of this same expectation.

Academic advising

While both groups of students clearly felt they did not receive adequate departmental orientation when beginning graduate school, there was a great deal of 
difference in how the two groups perceived the overall academic support that they had received. The traditional / linear trajectory students were much quicker to express displeasure and negative experiences that they had with their advisers or department than the broken trajectory students. As discussed in the traditional / linear trajectory section, four of these students recounted stories of advisers that were unavailable to them. Interestingly, none of the broken trajectory students shared this type of story.

\section{Other support}

Both traditional / linear trajectory and broken trajectory students noted the importance of outside-of -school support systems in regards to graduate school success. And while students in both groups mentioned receiving valuable support from their families, only the traditional / linear trajectory students mentioned that their parents provided financial support in regards to helping pay for their educations. 


\section{Confidence about Completing Program}

Figure 11

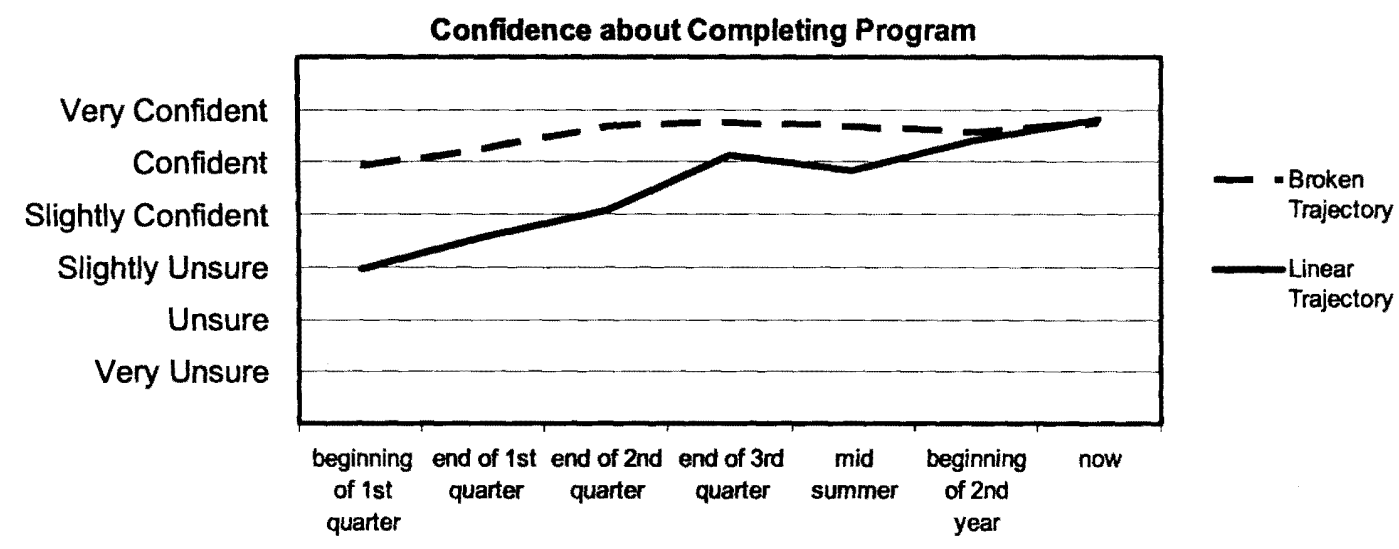

While almost everyone in both the traditional / linear trajectory and the broken trajectory groups expressed some feelings of apprehension in the beginning of their program, there were only two students that felt that they had a serious crisis in confidence in regards to their perceived ability to complete their master's programs. Interestingly, both of these students were from the traditional / linear trajectory group. One student admitted:

"I seriously considered leaving the program and going back (home) (at the end of the first term) and I almost did it. I am happy that I didn't, but I was close. I had a horrible first year here, especially fall term. It was horrible. I hated it." (traditional / linear trajectory, female, 23: TLT-3)

Interestingly, while several broken trajectory students reported concerns about whether they fit into graduate school at the beginnings of their programs, none of the 
students in this group questioned whether they would complete the program. They knew they would.

\section{Feelings of Connection to Department}

The general consensus among all the students from both paths was that their feelings of connection to their departments increased over the time they spent in the respective master's programs. Only one traditional / linear trajectory group student varied from this pattern. She reported initially feeling disconnected from her department and that her low feelings of departmental connection remained steady throughout her time in her master's program. She attributed these feelings to the fact that she did not receive a graduate assistantship upon beginning her program. In addition, because some faculty left PSU to take positions at other schools, she believed that the remaining faculty in her department were overworked and therefore, less available for students without assistantships like herself.

The primary difference between the groups was not in how they reported their feelings of connections, but in how they described their feelings. Traditional / linear trajectory students voiced a sense of a community perspective in their narratives. Three of the students in this group used the collective pronoun "we" when telling their stories of early feelings of connection:

"In terms of socially, no we didn't feel connected, but I think it goes back to that we had a small class and we all had jobs so there was no true social interaction." (traditional / linear trajectory, male, 24: TLT-6) 
The broken trajectory students were much more likely to personalize their narrative accounts:

"At the end of the first term, I felt like I belonged a little more. I had gone out for food with a couple of my peers, and we had studied together, so I felt that we knew each other at least a little." (broken trajectory, female, 32: NTBT-1)

Interestingly, the one time a broken path student used a more "objective" voice (i.e. the pronoun "you" in a narrative), she then changed over to the more personalized "I" within the story:

"If you want individual attention you have to seek it out because it is rare that you are going to be given individual attention so in terms of belonging I feel that I belong because I have pursued that. I have gone to different events and I've sought out to seek to my professors individually just about specific questions and general questions and just to talk I feel that I have sought out different people in the program to hang out with or to study with or to form study groups with." (broken trajectory, female, 27: NTBT-3) 


\section{Feelings of Legitimacy}

Figure 12

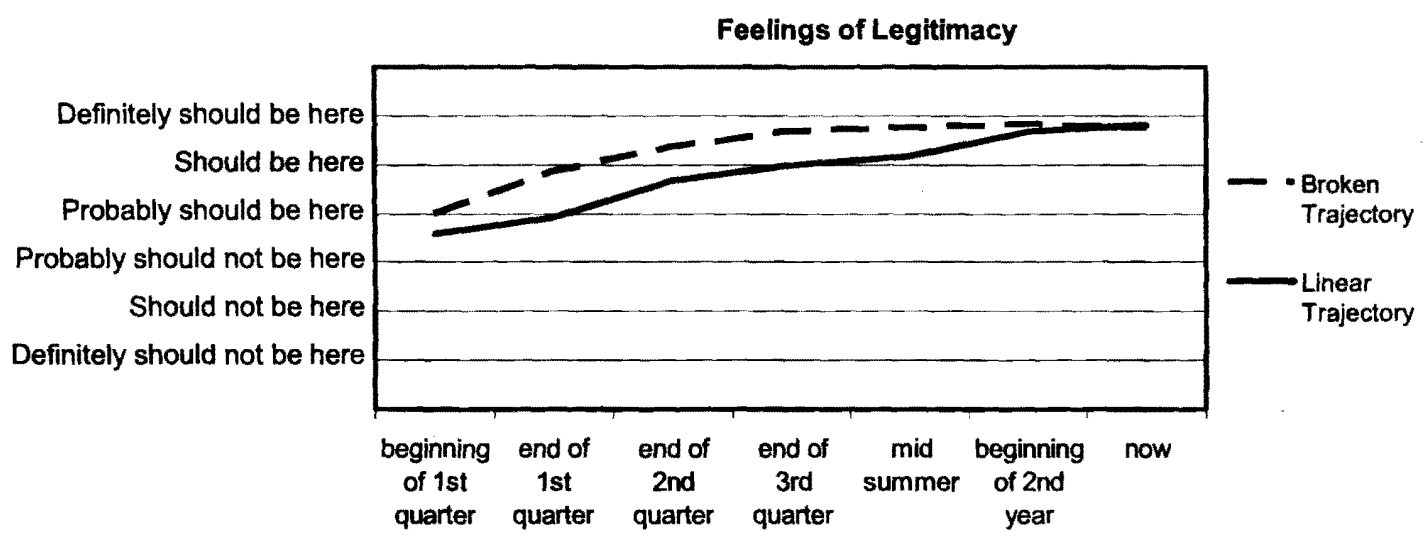

Overall, there were questions about legitimacy from both groups of students.

While there were a couple of students in the traditional / linear trajectory group that reported feeling like they were legitimate graduate students from the beginning of their programs, many of the students in that group expressed very strong concerns about whether they fit in to graduate school. The broken trajectory students all expressed concerns about their legitimacy as "real" graduate students, yet they also were clear about their motivation not just for being in school, but for completing their respective programs. This sense of purpose appeared to alleviate some of their initial concerns and, over time, served to increase their feelings of legitimacy.

\section{Conclusion}

This chapter discussed the results and findings from the interviews conducted for this study. It broke the results down into two primary sections: broken trajectory and traditional / linear trajectory. Within these two sections, support, confidence in 
completing the program, feelings of connection with the department, and feelings of legitimacy were discussed.

The following chapter will approach the research questions and examine the key findings from this chapter. Implications of this study, limitations, and areas of potential future research will also be presented. 


\section{CHAPTER 5: Discussion}

In chapter two, four major research questions were presented:

1) How do the experiences of two groups of masters students - one group who followed a traditional path (i.e. linear trajectory) and another group who took a break in their education prior to starting graduate school (i.e. broken trajectory) -affect students' confidence in their ability to complete the program?

2) How do differences in the educational path that master's students take affect students' feelings of connection to their program?

3) How do differences in the educational path that master's students take affect students' perception of legitimacy?

4) How do differences in the educational path that master's students take affect these students' knowledge of the graduate student role?

How students answered questions one, two and three were discussed in the previous chapter. But what does it mean? How do their answers fit with previous research? Perhaps most importantly, how does it all fit together to answer question four?

This chapter has four sub-sections - one for each of the four research questions. Sub-section one starts with a graphic representation of the main similarities and differences associated with research question one: how confident did they feel about completing their master's program? The text begins by discussing the themes found in students' responses. First the themes from the narratives of traditional / linear 
trajectory students will be discussed, followed by those from the broken trajectory students' stories. This sub-section concludes with an analysis of the similarities and differences in themes between the groups that is used to understand these students' experiences in greater depth.

Sub-sections two and three follow the same pattern as sub-section one, in regards to exploring students' responses associated with the second and third research questions, which focus on feelings of connection to the departments and of legitimacy, respectively. The fourth sub-section will combine what was learned in the discussions of research questions one, two and three to try to answer question four: how do differences in educational experiences affect what traditional / linear trajectory and broken trajectory students come to understand as the graduate student role and how that understanding develops. 


\title{
FIGURE 13
}

\section{Confidence in Completing Program}

Similarities and Differences

\author{
between \\ Traditional / Linear Trajectory Students \\ and \\ Broken Trajectory Student
}

\section{Similarities}

- Students in both groups began their respective master's programs with feelings of insecurity about whether they fit in with their departments

- Students in both groups had initial concerns about their ability to perform academically at a master's level

- Both groups of student reported that their feelings of connection to their department increased over time
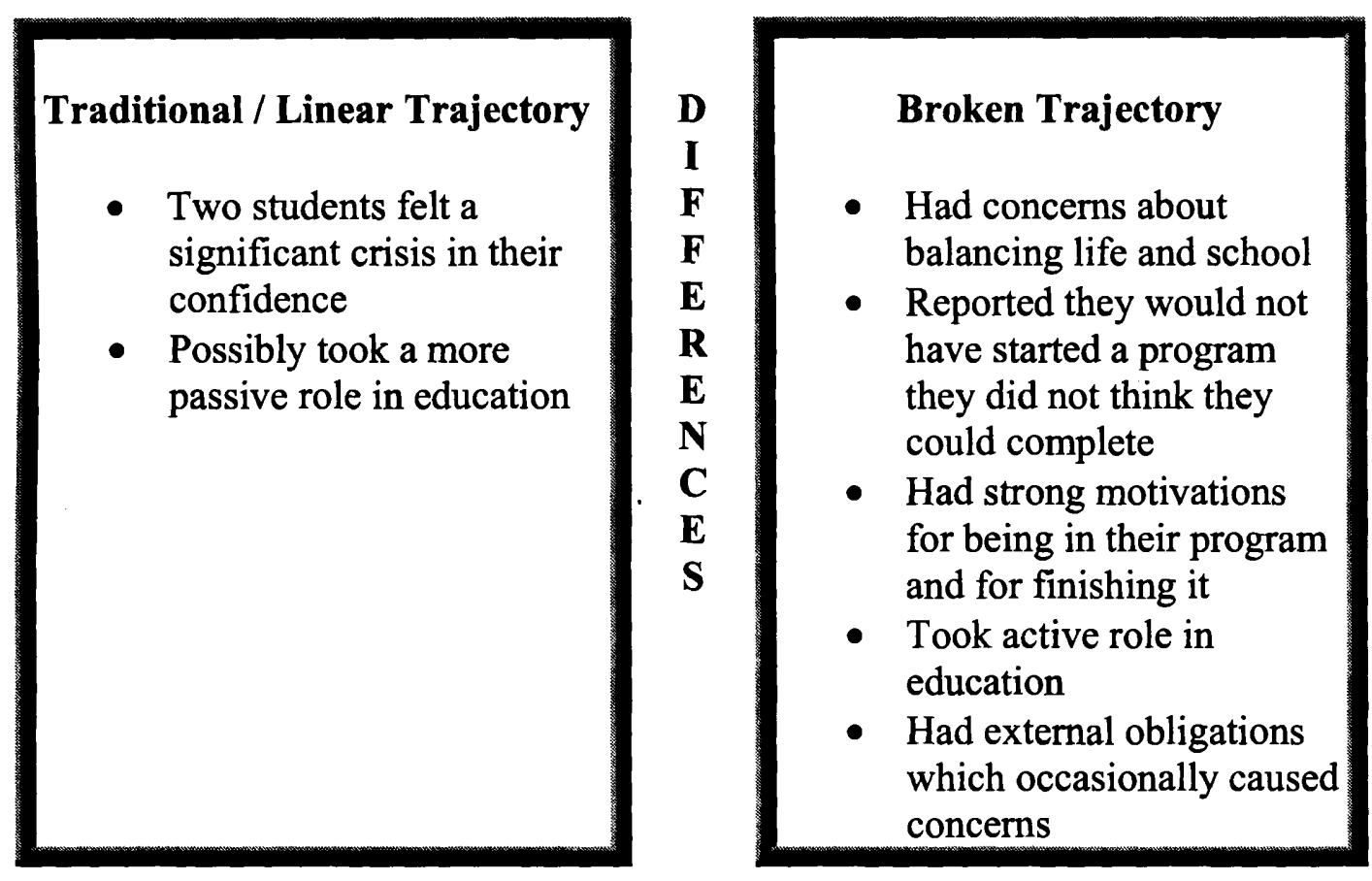


\section{Confidence in completing program}

Traditional / linear trajectory students

Overall, the traditional / linear trajectory students felt that their confidence in completing their programs increased during their time in school. They all felt some concern about their capabilities upon starting graduate school, but for the majority, these concerns passed very quickly, often within the first term. As one student explained:

“At first I was, again before class started, I got trepidatious about it, like was it going to be very different? Was I up to the challenge? Was it going to be all these really intimidating peers that $I$ am not going to be on the same level with? But, like I said, when classes started I felt very comfortable about being up to the challenge and not having a big disparity between the last class as an undergraduate and the first class as a graduate. I felt like it was a fairly good transition." (traditional / linear trajectory, male, 25: TLT-4)

Another student expressed a similar sentiment that after the initial fear, the confidence came quickly: "Before I started class, I had no idea of what was going on. I was pretty scared. I had no idea what to expect. But once I got into class and talked with other students and looked at the book, it was like 'I've done this before' and it was no big deal." (traditional / linear trajectory, male, 24: TLT-6).

Two of the traditional / linear trajectory students suffered a greater sense of a crisis regarding their abilities to do graduate-level work which caused them to think 
about leaving their respective programs. The crisis, for both of these students, revolved around the decision to attend this particular program at this particular time. While these students feelings of crisis were greater in intensity than the concerns of the other participants, both of them successfully overcame those concerns by the end of their first year. Interestingly, while both students were females, they differed in other important ways. "Age" was one difference. One was the youngest student in their group; the other was the oldest. "Living arrangement" was a second difference. One student was married and lived husband; the other was single and had room-mates. Identity theory offers insights into both of these students' issues. The married student had an issue with role conflict: role conflict is a special form of social conflict that takes place when one is forced to take on two different and incompatible roles at the same time (Lockwood, 1958). In regards to Burke's model of identity control, she cannot decide which role - student or mother -- she SHOULD be paying more attention to. For example, when asked why she had questions in the beginning of the program about her ability to finish the program she responded that she was questioning her choice to go to school rather than to follow the path of becoming a mother as soon as possible. Her crisis was not as much about whether she could successfully enact the graduate student role, but whether she should be prioritizing being a graduate student over her mother role, where her family standard was that she should "have four (children) by now" (traditional / linear trajectory, female, 26: TLT2). 
The second student's crisis was centered on the graduate student role. Now that she was in graduate school she was experiencing high levels of discrepancy between her role standard and the feedback she received for her role-related behavior. Her standard came from her undergraduate experience at another university, where she had been very active and successful in her home department and was very well liked by both the faculty and her peers. When she began her master's program at Portland State, nobody seemed to know or care about her undergraduate success, and she did not perceive the people in the program as welcoming. In her mind, neither her professors nor her peers liked her. She ultimately reconciled her perceptions of her professors' apparent uncaring attitudes with a view that those in program did care about her by framing her initial experiences as a "rite of passage." It was not that the professors in her program did not like her; instead, they were preparing her for the "real world." In regards to relationships with her peers, as the cohort of graduate students who were there before her completed their degrees and left, she found herself more in the position of being one of "the big dogs" that were looked to for advice by incoming students. This "self-referential feedback from others about how she was enacting the role" fit better with her standard of a "good graduate student," and therefore she subsequently felt less distress.

\section{Broken Trajectory Students}

The broken trajectory students all reported high levels of confidence in completing their master's degrees throughout their time in their programs. They all, 
directly or indirectly, indicated that they would not have begun a master's program that they did not feel confident that they would complete. This seems to indicate that they had thought through their decisions to attend graduate school, and anticipated facing adjustment issues. Even though these students struggled in regards to questioning certain specific abilities at times, this questioning did not diminish their belief that somehow or other, they would finish. They also had strong motivations for completing their programs. One, whose husband had died, realized that her teenage daughter would be leaving home in a couple of years and she wanted a career that she could love to focus on. Another, having lost her job, felt that this was her opportunity to follow her passion. Having these motivations allowed them to persevere in the face of adversity, and may have mitigated some of the detrimental effects of doubting their abilities at times. This suggests that for broken trajectory students, that the ability to look at a long-term goal may alleviate the stresses caused by the short-term difficulties of a class, or a quarter.

\section{Similarities}

Students in both the traditional / linear trajectory and the broken trajectory groups began their respective master's programs with questions and feelings of insecurity about whether they fit in to their departments. Both groups of students also reported that their feelings of confidence in completing their programs increased over time. One of the traditional / linear track students explained her increase in confidence in completing the program like this: "Partially (it was) just the fact that I knew, having 
gone through enough school, that one school year goes by really quickly. So I knew that I had a year left but it was going to fly by and I was going to be able to get things done" (traditional / linear trajectory, female, 26: TLT-2). One of the broken trajectory students described her confidence, or determination, in completing the program: "After this really hard class, I thought 'well, I am in it now!"” (broken trajectory, female, 42: NTBT-2).

\section{Differences}

The two groups differed in a number of areas regarding their confidence in completing their programs. The only students that had major crises regarding their levels of confidence were both traditional / linear trajectory students. While the majority of the traditional / linear trajectory students did not feel this crisis, none of the broken trajectory students had this experience. As one of the broken trajectory students explained:

"I have other experiences that I can bring to this. I know how to delegate my time efficiently, at least as far as work goes... So l've done things in my life before that have been infinitely more miserable than staying up all night to finish a paper, not getting enough time to work out, or missing dinner because I've got to do a paper... I don't even blink an eye" (broken trajectory, male, 35: NTBT-6)

Having 'life-experience' may have made the broken trajectory students more confident in handling the challenges faced in graduate school. It may be that, because 
of their experiences outside-of-school, they have more instances of over-coming apparently insurmountable obstacles through hard-work that they can recall and then compare to their current graduate school situation than the traditional / linear trajectory students do.

Another possible explanation for why the traditional / linear trajectory students were more likely to experience a crisis in their relative confidence levels while the broken trajectory students did not may have to do with differences in students' expectations about what constitutes "appropriate" levels of advisers' and professor's support. Comparing the two groups of students, the traditional / linear trajectory students were much more likely than the broken trajectory students to tell stories of feeling unsupported; in fact, four of the six traditional / linear trajectory students told these stories whereas none of the broken trajectory students did.

An additional area of difference between the two groups was the broken trajectory students' greater concern about their ability to balance school and their lives. This concern seemed to have more to do with differences in obligations rather than differences in support. All of the students from both groups had good external support, but the broken trajectory students reported much higher relative levels of external obligations. Of the six broken trajectory students, all had significant situational barriers to success; three were married, one was a single mother, and the other two had moved out of significant relationships while they were in the master's program. Of the six traditional / linear trajectory students, only two reported situational barriers to success; one was married, and another reported being in a 
significant relationship, but since both partners were students, dealing with graduate student role demands might be relatively easier as they were both facing the same issues. Previous research has established (e.g. Witherspoon and Nickell, 1991; Sissel et al. 2001), that situational barriers negatively impact graduate student success. In this study, situational demands caused issues for broken trajectory students at a level much greater than that experienced by traditional / linear trajectory students. 
FIGURE 14

\title{
Feelings of Connection to Department
}

Similarities and Differences

\author{
between \\ Traditional / Linear Trajectory Students \\ and \\ Broken Trajectory Student
}

\section{Similarities}

- Both groups experienced an increase in feelings of connection to their department

- Both groups understood importance of social connection with both peers and faculty
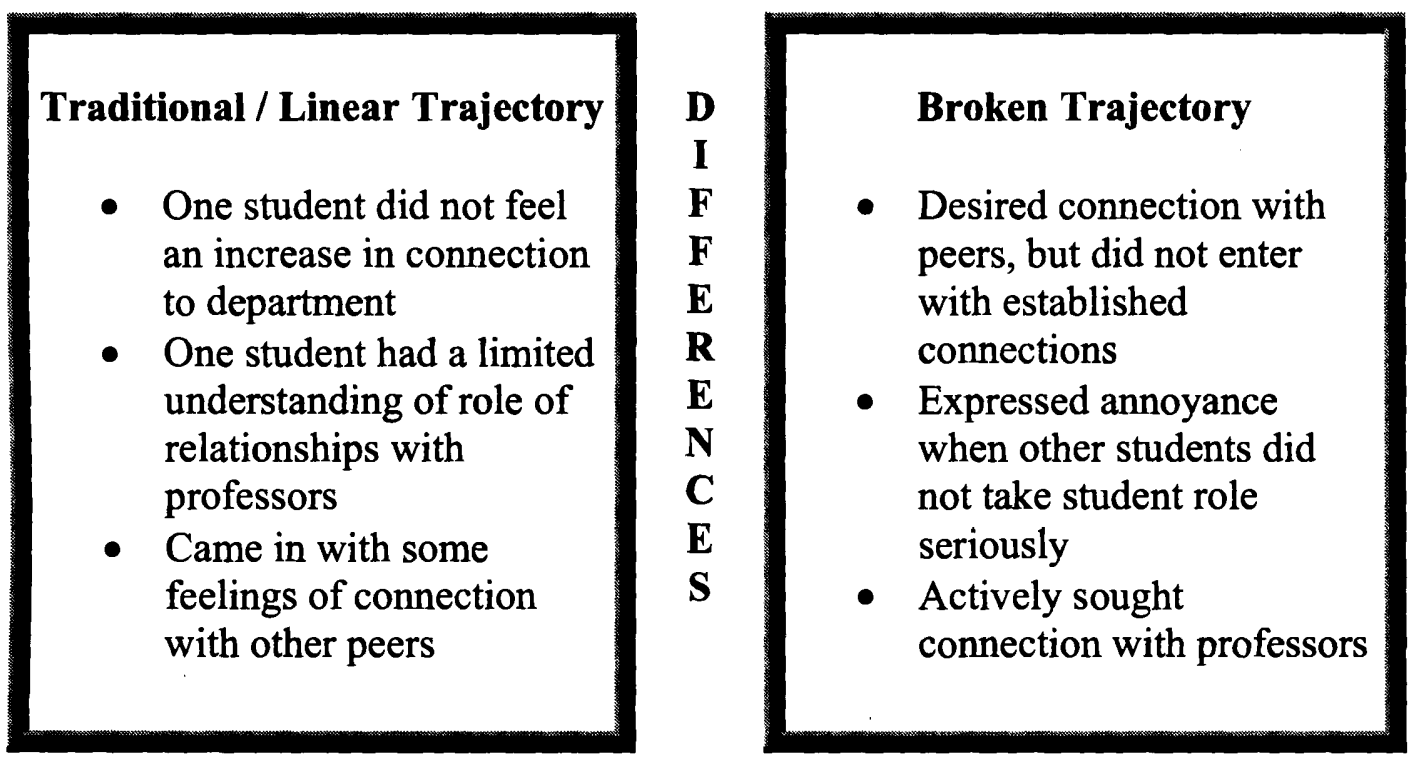


\section{Feelings of Connection to Department}

\section{Traditional / Linear Trajectory Students}

Overall, students in the traditional / linear trajectory group began their programs not feeling very connected to their departments. These students seemed aware that 'connection' had both an academic and a social component with other students and with faculty. They had more confidence about the academic component and were more likely to downplay the social component with faculty and other students. One student described how he felt about his connection to his department at the end of his first term: "Academically, sure, no problem. But in terms of knowing professors and interacting with other students there was no change at that point" (traditional / linear trajectory, male, 24: TLT-6)

All but one of the traditional / linear trajectory students felt that their connection to their department increased over time. A student who had a particularly difficult transition into her program stated that "things have really turned around as far as that goes and now when there is an event the faculty come to me and my friend and say 'can you help?' I feel a lot more like I belong” (traditional / linear trajectory, female, 23: TLT-3). Another student attributed his increased connection to the department to his position as a teaching assistant. That responsibility encouraged him to "hang out with all of these people (other TA's)" which in turn "there was a sort of confidence after getting to know undergraduate students and getting to know professors and getting encouragement from professors" (traditional / linear trajectory, male, 25: TLT-5). 
The one student who reported that she did not feel an increase in connection to her program either in regards to the academic or the social components, stated she did not feel significantly connected to either her peers or her professors. She did not feel like she fit in with these peers because she did not have the same life experiences or academic background that allowed these students to excel. She felt that the other students in her program were better prepared for graduate level work. This was because, according to her, they were from "privileged backgrounds." She also did not feel connected to her professors. She attributed her feelings of lack of connection with faculty to personnel issues. There were several faculty members who left her department during her first year and none had been replaced at the time of her interview. This student felt that the remaining professors were so overworked that they did not have the time, nor the energy, to help graduate students such as herself. While admitting that there were outside influences on the professors time (e.g. too few professors for the amount of work), she still blamed the department for not doing more to make her feel connected.

Another student demonstrated a limited understanding of the importance of his relationship with faculty, even though his feelings of connection to his program increased in a comparable manner those of the other students in his group. He did not envision his relationship with his professors as more than the faculty members' ability to write him letters of reference when he applied for a job. Even in that situation, he stated that he felt as if his work experience would be more valuable in finding employment than the letters. This student's feelings of connection to his program were 
based on his relationships with his peers. He had a graduate assistantship that afforded him a fair amount of time interacting with the other students in his program. As he became closer to his peers, he reported his feelings of connection to the department increased.

\section{Broken Trajectory}

The broken trajectory students all felt an increase over time in their levels of connection to their departments. Many of them reported starting their master's programs not feeling very connected, and stated that they had questions regarding their ability to fit in. There were a few broken trajectory students who noted they had concerns about being older than many of their peers, but the issue of age differences was not a large concern for the majority of the students in this group.

Relationships with peers were an important component of broken trajectory students' graduate school experiences. Three of these students directly discussed looking forward to having the opportunity to connect with like-minded peers. As one student stated:

"I wanted grad school to be that kind of thing where I could meet other people who were really interested in being a professional (department), and so that's what they ate, slept and drank... and so we could connect on those levels, or commiserate, or whatever." (broken trajectory, male, 35: NTBT-6) 
This expectation that graduate school was going to consist of interactions with dedicated and serious peers may help explain the confusion and annoyance that these students expressed when they saw other graduate students who were not taking the role seriously. It was clear that other students in their classes did not sometimes meet the broken trajectory students' graduate student role standard. This did not cause the broken trajectory students to question their own standard; it only made them question why the other students were in school.

Faculty were paramount to the broken trajectory students' feeling of connection, but these students expected to have to actively pursue these relationships. They came into their master's programs empowered and prepared to engage the faculty, although how they did so varied from seeking interactions outside of the classroom setting to active participation within classroom discussions. The attitude of the broken trajectory students was that they had something to offer the professors and department, and that they were not looking to have their education be a 'one-waystreet.' As one student explained "I had the sense that my time, my conversation was not done once the term was over. In fact, you know, I am still emailing and talking with one of those professors a year and a half later, and I haven't had any other classes with him" (broken trajectory, female, 36: NTBT-4).

\section{Similarities}

The primary similarity between the traditional / linear trajectory students and the broken trajectory students was that both groups experienced an increase in their 
feelings of connection to their department. As one of the traditional / linear trajectory students stated:

"The more that you do that (getting involved) the more you feel that you know people and feel confident in the work that you are doing... that other people know you... that you show up to something and that someone is going to know you" (traditional / linear trajectory, female, 26: TLT-2).

One of the broken trajectory students expressed a similar sentiment this way: "I guess it has just been getting to know people, and not feeling like they don't have any idea who I am" (broken trajectory, female, 32: NTBT-1).

\section{Differences}

There were two noteworthy differences between the groups in how they perceived their connection to their departments. The first is that broken trajectory students expressed a sense of agency when they discussed pursuing opportunities to develop connections within their department:

"Students ..., especially graduate students, they are the ones that set the tone for the community, or lack thereof, that the department is going to have at any given time and it is always changing... so I came in fully empowered and ready to do that." (broken trajectory, male 35: NTBT-6). As discussed earlier, the traditional / linear trajectory students did not tell the same types of stories when discussing connection; they were much more likely to tell 
stories of times that their advisers or professors were not available to them or had not been helpful. This raises an interesting question: did broken trajectory students actually receive more support from their professors or did they just perceive the support they received as appropriate while the traditional / linear trajectory students did not? On one hand, it is possible that, because broken trajectory students took a more active role in seeking out their professors, these students may have received more support. On the other hand, perhaps the broken trajectory students had similar experiences with professors being unavailable, but it was how they interpreted these experiences that was different. Using attribution theory, the broken trajectory students, when they experienced faculty being unavailable, would have attributed the oversight to the professor being busy. The traditional / linear trajectory students appeared to attribute the unavailability to a personal reason ('I was not important enough'). These attributions of the professors' behavior influenced what was considered an important story to tell during the interviews. For the broken trajectory students, because these events were not viewed as "inappropriate professor role behavior," they were not seen as worthy of telling.

The second difference between the two groups was how they presented their stories about connection. The traditional / linear trajectory students used a community perspective discussing how "we" did not feel connected. This implies a sense of connection with the other students, even if it is on a limited basis. Perhaps because they had shared a common undergraduate student role recently, they were more easily able to consider themselves part of a group of graduate students. The broken trajectory 
students almost exclusively personalized their stories. They discussed how "I" felt or did not feel connected. This may reflect the individualized educational path each of these students followed. While the broken trajectory students felt a connection with their peers, even in their narratives they maintained a personalized perspective. 


\title{
FIGURE 15
}

\section{Feelings of Legitimacy}

Similarities and Differences

\author{
between \\ Traditional / Linear Trajectory Students \\ and \\ Broken Trajectory Student
}

\section{Similarities}

- Overall, students in both groups began their respective master's programs with questions about their legitimacy

- Both groups questioned their academic ability at times during their program

- Both groups expressed an increase in their feelings of legitimacy
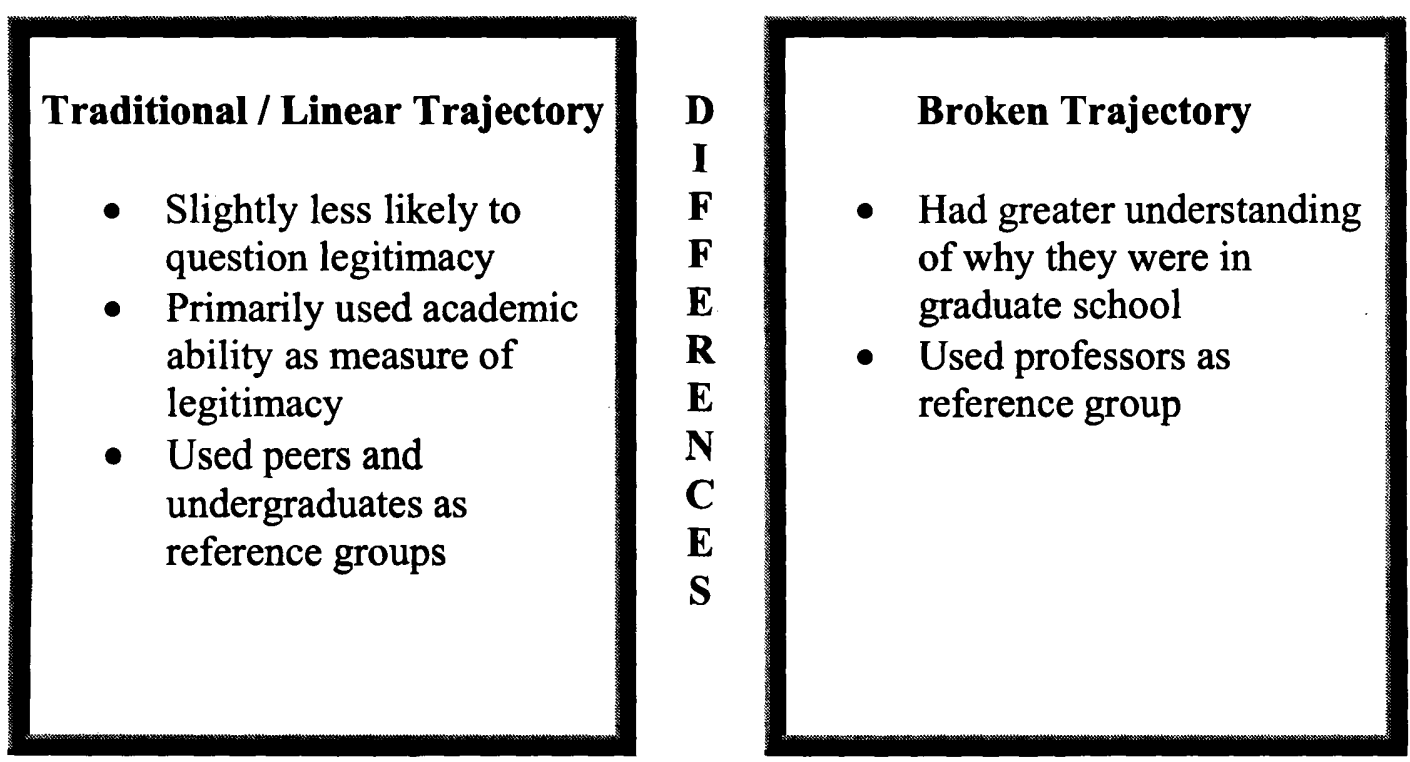


\section{Feelings of Legitimacy}

\section{Traditional / Linear Trajectory}

Overall, the traditional / linear trajectory students reported that their feelings of legitimacy increased during their time in their respective master's programs: "I started out not feeling very legit at the beginning of the program. I kind of maintained that through the first and second quarter... some of the increase (after that) has to do with classes that are relevant to me and that are part of my area of expertise" (traditional / linear trajectory, female, 25: TLT-1). Two of the students associated legitimacy almost exclusively with being able to compete academically: "legitimate (is) being up to the challenge again, giving a good performance" (traditional / linear trajectory, male, 25: TLT-4). Interestingly, as the first term progressed for one of these and he got feedback based on his performance in his classes this student reported increased feelings of legitimacy: "that first class is... some of the kids in there didn't know what they were doing. It was pretty much an ego boost. Some of the kids didn't know what they were doing at all. I got pretty good grades from there on out." (traditional / linear trajectory, male, 24: TLT-6). The other student stated he started with a high level of feelings of legitimacy and that level stayed high throughout his program. He claimed to never have questioned his legitimacy:

"there really hasn't been a time when I felt that 'that person is way ahead of me' or 'what am I doing here? I am out of the loop' You know, I have always felt legitimate, to use that term... I don't think that has ever diminished in spite of the natural doubts that come along or 
challenges as the case may be. It can be discouraging, you know we all wish we could be at the top of our game all of the time, but I don't think I have ever had that (sense of legitimacy) go down" (traditional / linear trajectory, male, 25: TLT-4)

\section{Broken Trajectory Students}

All the students in the broken trajectory group expressed some concerns about their legitimacy as graduate students at some point during their program. All of them also felt that their feelings of legitimacy increased over time. While this was the trend, most of these students also questioned what was meant by the term "legitimate." As the research was designed to be exploratory, this definition was left up to the participant, with only the prompts of the graph "should be here - should not be here." When asked, the researcher encouraged the participant to explain their interpretation. One of the students had talked extensively with her peers and professors about issues revolving around her feelings of legitimacy. As she came to see the question:

"it's not about whether or not I should be at a learning institution; it is more what is it going to take for me to feel like I have the right to label myself a scholar or researcher, an intelligent member of my discourse community?" (broken trajectory, female, 36: NTBT-4)

This interpretation of legitimacy unfortunately came too late in the research for inclusion into the interview guide, but it sheds some light onto how these students 
were thinking: legitimacy had less to do with whether they "should be here" and more to do with whether they had the right to legitimately claim that they should be here.

Another student felt his feelings of legitimacy decrease when he went to a conference in his field. He explained it this way:

"there were people there from Stanford, Brown, Yale... that was a little bit daunting. So, sometimes I don't feel legitimate in the field in general... I think it has to do with my own fears and stuff." (broken trajectory, male, 35: NTBT-6)

The broken trajectory students also expressed a greater understanding of 'why' they should be in a master's program. This understanding had little to do with grades or academic aptitude (although that did play a role), but had more to do with the amount of work that they had already put into it and the hoped for outcomes. Five of these students discussed that they 'loved' the academic environment, even when they felt pushed to their limits at times. This passion for school, combined with having a greater understanding of their motivation for being in school may be a mitigating factor against the detrimental effects of questioning their legitimacy.

\section{Similarities}

Both groups of students had some questions regarding their legitimacy as graduate students. Questioning their academic ability was a common theme for students in both groups. This question of academic ability was assuaged for most students within the first term. As one broken trajectory student explained about her 
feelings of legitimacy "just at the beginning... I felt like 'I am not sure. Let's test the waters out.' But by the end of my first quarter, I know what teachers expect, I am doing ok" (broken trajectory, female, 27: NTBT-3)

\section{Differences}

For the broken trajectory students, their feelings of whether they had a legitimate claim to being a graduate student may have come from having an undeveloped, or perhaps naïve, sense of what a successful graduate student would look like. Five of the broken trajectory students mentioned that professors were preparing them to be peers. Of these five, two felt that the professors were already treating them as peers, or expecting them to act as peers.

While they may be close in age to many of the professors, they were not at the same academic level as the professors. This caused feelings of concern prior to the start of the program for one of the students: "the hardest part I thought was going to be living up to the professors' expectations. I felt like they had given me this opportunity to be here and that they would regret letting me in" (broken trajectory, female, 32: NTBT-1). The broken trajectory students did not seem to have the perspective of development that the traditional / linear trajectory students discussed:

"(the professors) were pretty clear as far as 'this is our plan: we are kindof bringing you along into the program' so there wasn't a whole lot of anxiety of having to be awesome right away. It was more like I need to learn to be at this level" (traditional / linear trajectory, male, 25: TLT-5) 
For the traditional / linear trajectory students, having an understanding that there was a 'level' that was appropriate for a master's student that was different from the professors 'level' helped diminish fears. These students seemed to accept that they were going to make mistakes and did not worry that their professors would judge them as unworthy master's students. While the broken trajectory students did not directly worry about being labeled 'unworthy' it may have been implied:

"the first few assignments are always tricky. You've never had this professor before. You've never been in this program. You don't know what they want from you. You don't even know if you understand the assignment fully and you are afraid to ask because you don't know them very well" (broken trajectory, female, 27: NTBT-3)

The two groups appeared to use different reference groups to understand the role of legitimate graduate student. The traditional / linear trajectory students not only referenced each other, but also referenced undergraduates. In this regard, they were able to see themselves as very capable and worthy of being a master's student: “that first term I felt like I was still an undergrad, I hadn't pushed through... after that I figured out that I was not just here to go through the motions, I had to figure out where I was going. I now find undergraduates completely annoying. I think that as an undergrad I did the bare minimum. As a grad student you don't skip steps. And talking in class, you can't say things that are going to make you sound stupid. Undergrads can say whatever they want, but as a grad student you are 
working with people that are going to you're your colleagues in the future." (traditional / linear trajectory, female, 25: TLT-1)

The broken trajectory students referenced their peers, but referenced professors to a greater degree than the traditional / linear trajectory students did. As one broken trajectory student explained how she learned to see herself as legitimate:

"I was searching for someone to give me an answer: 'this is how you will feel 'legitimate" and after talking to faculty after faculty after faculty and student after student after student, I was like 'right, this is something I'm going to have to do for myself'... there may be times where I feel like 'wow, I did a really bad job,' or 'I fell short on this,' or 'I didn't do that well' but that's a one time thing, and perspective...perspective." (broken trajectory, female, 36: NTBT-4)

All four of the males in the research, regardless of the group they were in, expressed fewer questions regarding their legitimacy compared to the females in the research. This research was not designed to look specifically at gender issues for master's level students. Therefore, there is not enough information from the interviews to claim that there is a gendered issue within feelings of legitimacy in the master's level students, but the potential for this is there. This would align with much of the research on the Imposter Phenomenon, where females are often found to be more likely to experience feelings of fraudulence than are males (e.g.: Clance, 1978; Reis, 1987; Fruhan, 2002). 
FIGURE 16

\title{
Knowledge of Graduate Student Role
}

\section{Similarities and Differences}

\author{
between \\ Traditional / Linear Trajectory Students \\ and \\ Broken Trajectory Student
}

\section{Similarities}

- Transition into Graduate Student role difficult for all students

- Both see the Broken Trajectory students as 'serious' students
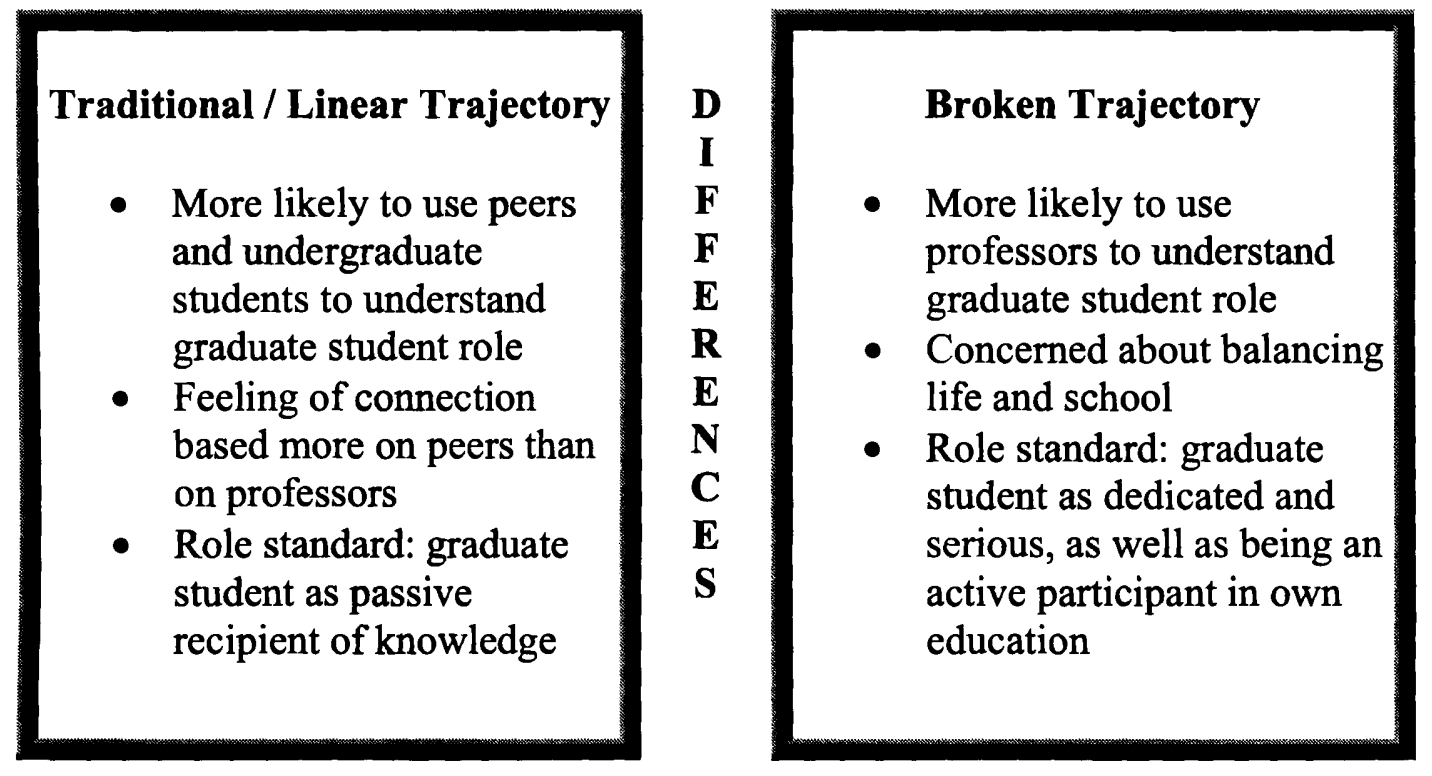


\section{Knowledge of the Graduate Student Role}

This final section looks at the final research question in this study: how do differences in the educational path that master's students take affect these students' knowledge of the graduate student role? The original premise of this study was that there are significant differences between broken trajectory and traditional / linear trajectory students' experiences in graduate school, which should result in differences in the knowledge of the graduate student role. This study has shown that there are differences between the students in how they enact the role, but the results from these interviews can not definitively answer the question of how the path that a student takes through higher education affects how the students understand the master's student role. That said, there are a few insights that can be considered based on the results already discussed.

Transitioning into the graduate student role posed problems for all of the students in this study. This shows that becoming a graduate student is experienced as qualitatively different from whatever understanding that the individual had about being an undergraduate student, regardless of whether the student moved directly from undergraduate to graduate school or the student took a break before starting a master's degree program. As Ralph Turner noted: "transitioning into a role with pervasive significance for personal behavior can often be a stressful experience" (Turner, 1978; 4). Even though it had originally been expected that students who had more recent experiences as 'undergraduate students' would experience an easier transition to the graduate student role this proved not to be the case for the students in this study. It 
appears that the role of 'master's student' is significantly different from the role of 'undergraduate student' and success in that one does not directly lead to success in the other. This finding supports Tinto's suggestion that models of undergraduate persistence may not be applicable for describing graduate students' experiences: "Unlike undergraduate persistence, the process of graduate persistence can not be easily described by any one simple model" (Tinto, 1993; 238).

There were some differences in how the two groups understood the graduate student role. One difference had to do with the explicitness of the role standard; broken trajectory students clearly articulated their expectations of themselves and other students while traditional / linear path students seemed to share an implicit assumption that "everyone else is like me" without providing details as to what the specific expectations of the role might be. This lack of clarity in what the traditional / linear trajectory students expected from their peers may reflect a lack of certainty in what was expected of them. It is also possible that this lack of clarity suggests that these students were still using their undergraduate role standard as their standard for their graduate student role; they took for granted that expectations were the same as they had been in their undergraduate schooling. In their discussions of "feelings of legitimacy as graduate students," what appeared to be the shared elements of the graduate student role was that everyone seemed confused as to what was expected of them. Broken path students may have had questions as to what professors expected of them, but they were clear as to what they expected of themselves and other graduate students. 
A second difference had to do with whom the two groups of students considered an appropriate reference group. The traditional / linear trajectory students used their peers, as well as undergraduate students, when trying to determine what a successful master's student is. The broken trajectory students used their peers to an extent, but also used professors for that reference. This difference may help explain why the broken trajectory students felt more connected to the department than the traditional / linear trajectory students did. As professors are intricately linked to a department, students who align themselves with the professors are more likely to feel connected. In terms of Burke's and Collier's models, students who use the role standard of a reference group (i.e. professors) who have the power to decide which role-related behaviors are seen as appropriate or not, should receive positive selfreferent feedback about their behavior and subsequently feel more connected to their department.

Collier's differentiated model $(2000,2001)$ can also help explain how there may be a difference in how the two groups of students understand the role of 'graduate student' based on the nature of each group's respective role standard, in this case "student as a passive recipient" versus "student as an active participant." The broken trajectory students expressed an understanding that they needed to be active participants in their education. They discussed "seeking out" opportunities to participate in graduate student orientations and to interact with professors:

“...I purposefully sought that (university orientation) out and took advantage of that. Then I went out of my way to get involved in the 
(department honors society) chapter that is here and it is still an ongoing process. I am still trying to get relationships with people in certain departments that are related in some way to (my field)." (broken trajectory, male, 35: NTBT-6)

However the traditional students seemed to expect that the professors in their program should be the ones actively seeking out students to offer advice:

"Its not like they are not friendly and willing to discuss it, there is just no proactive work on their end to make sure that you know what needs to be done" (traditional / linear trajectory, male, 24: TLT-6).

The broken trajectory students also used a graduate student role standard that included an element of 'dedication.' This dedicated version of graduate student was manifest in behaviors that included participation in class, being able to bring in material beyond the required readings for discussions, and always being prepared.

Using Burke's model, it is clear that the broken trajectory students' model of graduate student worked better than the model used by the traditional / linear trajectory students, perhaps because that standard was closer to one used by the professors in their master's programs. The broken trajectory students used a more mature approach to being a 'serious' student, as reported by both groups. It could be that being 'serious' and having a clear understanding of their motivation gives these students the advantage of greater clarity regarding the appropriate standard to use, or it could be that their "serious" motivation was what professors were looking for in "successful graduate students." It is also possible that the need to balance school and 
life helps create a focus for the broken trajectory students that the traditional / linear trajectory students did not have. What is not clear is if the differences were based on the students' personal quality of maturity of if they had a more detailed understanding of the role standard used by the department.

This chapter began by discussing the results for three of the four research questions posed in chapter two. Each of the questions was examined from the traditional / linear trajectory perspective, the broken trajectory perspective and then the similarities and differences were explored. For the final question, it was suggested that while it is not possible to ascertain whether the path through higher education affected how the two groups came to understand the graduate student role differently, it is possible that the broken trajectory students actually have an advantage over the traditional / linear trajectory students in understanding the role closer to how the professors understand it. In the next, and final, chapter how the results of this study could be used in higher education will be discussed. Limitations and areas for further research will also be addressed. 


\section{CHAPTER 6: Conclusions}

This chapter will review the major findings of this research and discuss two important issues -- differences in perceptions of legitimacy and student success, and differences in goals and choices of role standards -- raised by this research. In addition, the limitations of the study will be discussed, identify areas for future research will be identified, and implications of the study will be examined. While this research focused on the master's students' knowledge of the graduate student role, much of what was learned had to do with how two groups of students understood their success through their confidence in completing their programs, their sense of connection with their departments, and their feelings of legitimacy as graduate students. Although both groups of students are already successful by the definition used in this research, having completed their first year in their master's program, how these students understand this success was different.

Both traditional / linear trajectory and broken trajectory students began their respective master's programs with feelings of insecurity about whether they fit in with their departments, and had initial concerns about their ability to perform academically at a master's level. A small, but significant, difference between the groups was that while they both reported that their feelings of confidence regarding completing their programs increased over time, the broken trajectory students started out with greater confidence about successfully completing their program. Broken trajectory students articulated strong motivations for success, to the point of noting they would not have even begun a master's program without a fairly high level of certainty that they would 
complete that program. This discussion of motivations, and how it related to program completion, was not present in the narratives of the traditional / linear trajectory students. While not found explicitly in their narratives, it did appeared that the traditional / linear trajectory students were motivated to complete their master's degrees, but that they did not consciously reflect upon this - almost as if it was taken for granted. This suggests that the two groups of students entered graduate school using different criteria for evaluating the likelihood of completing a master's degree program. The broken trajectory students treated graduate school as a discrete event; this was evidenced by the way that they consciously reflected on their chances of success before entering their master's programs. On the other hand, the traditional / linear trajectory students did not articulate conscious reflection on the question of whether they would complete their master's programs; instead they seemed to be following the successful momentum from their undergraduate experiences.

While both groups of students discussed the importance of external support in regards to completing their degree programs, broken path students explicitly discussed the difficulties they face in balancing competing demands of life and school, particularly in regards to the level of external obligations. While the literature is clear that multiple competing roles increases the challenges to success in graduate school, in this study it appears that these additional challenges may have helped sharpen the focus of the broken trajectory students. These students were much more articulate in identifying their reasons for being in school, and had obviously thought through their chances of success before entering their master's programs. Deciding to enroll in 
graduate school, even while knowing that they had to balance a greater combination of external obligations and academic obligations than their traditional peers, may have led these students to initially pay more attention to figuring out the expectations associated with the graduate student role as they may have figured they had smaller margins of error if they wanted to succeed in their master's programs. Preemptively compensating for what might be perceived as an additional problem may have served as an impetus towards successful degree completion for these students.

There were also differences in students' feeling of whether they were supported by the professors in their respective programs with regard to completing their degree. This manifested itself in discussions of students' expectations about what constitutes "appropriate" levels of advisers' and professor's support. The traditional / linear trajectory students were much more likely than the broken trajectory students to tell stories of feeling unsupported; in fact, four of the six traditional / linear trajectory students told these stories whereas none of the broken trajectory students did. This difference is important when considering how the different trajectories through higher education affect student success. Traditional / linear trajectory students place a greater importance on active support from their advisers and professors. Assisting these students may require greater proactive outreach than departments are currently used to providing.

Both traditional / linear trajectory and broken trajectory students reported understanding the importance of social connections with both peers and faculty, and both experienced an increase in feelings of connection to their department over the 
time they were in their master's programs. One difference was that traditional / linear trajectory students came into their programs with already established feelings of connection with their peers, as evidenced by their use of plural pronouns (i.e. "we") when discussing their graduate school experiences. This sense of connection can possibly be used as a foundation for both goal and institutional commitments as they positively relate to student persistence (Tinto, 1993).

On the other hand, while broken trajectory students expressed a desire to connect with peers, they did not enter graduate school having already established those connections. Interestingly, broken trajectory students consistently used individual pronouns (i.e. "I") in their narrative descriptions of their master's programs' experiences. These students may be at an initial greater risk for inadequate social connections. If these connections are not established, these students may have diminished institutional commitment (Tinto, 1993). While these students may not drop out from their programs, they may be less satisfied with their experience than they would be otherwise.

\section{The Issue of Differences in Perceptions of Legitimacy and Student Success}

Interestingly, perceptions of legitimacy could create different problems for each group of students. Traditional / linear trajectory students primarily used academic ability as the measure of their legitimacy as graduate students. This suggests that for traditional students, academic success, as shown by grades and classroom dynamics, not only allows these students to feel that they have what it takes academically but, on 
a deeper level, they believe that this confirms their right to be a graduate student. This standard is different to what is used by professors and departments to gauge graduate student success. During the first year of a master's program, students need to accomplish more than just good grades. In most programs the students must decide what their thesis or project will be and must have a committee put together by the end of the first year so that there can be independent progress made over the summer. Students who are only using grades and classroom dynamics to gauge their success may have a false sense of security that they are on track when in fact they are not performing the behaviors that they need in order to successfully complete their program.

Broken trajectory students perceptions that "professors are training us to be peers" could result in another problem. Perhaps because these returning students are not clear as to the difference in professors' minds between "graduate student as (almost) peer" and "other professor as peer" the broken trajectory students may be demanding too much of themselves. All of these students are enrolled in terminal master's programs, where the possibility of earning a Ph.D. is not an option. Yet the professors that these students are comparing themselves to are Ph.D.s. While using the professors as a reference group seemed to improve the likelihood of these students feeling more connection to their program, it may also have resulted in them expecting more from themselves than their professors actually expected. This has the potential to lead some students to experience greater stress and dissatisfaction with their performance. 
In the students' discussions of their relative levels of connection to their programs evidence of each group utilizing a different role standard began to emerge. Broken trajectory students understood the role standard of graduate student to include moving beyond basic classroom performance. These students were much more explicit in what they understood as appropriate graduate student behavior. This included participation and classroom performance, but it also included a sense of being a 'serious' student. Part of this student role included being an active participant in gaining the education that they were getting. Broken trajectory students expressed a sense of agency in their discussion of how they actively sought out interactions with faculty. In light of the traditional / linear trajectory students' expressions in question one that they felt unsupported by faculty, with the implication that it was the faculty's responsibility to seek students out in order to support them, it appears that these two groups of students understood the dynamics of professor-student interactions in widely different ways. The dynamics of professor-student interactions would be one of the major dimensions of any graduate student role standard.

Traditional / linear trajectory students stated that they used peers and undergraduates as the reference group for soliciting feedback as to their legitimacy as graduate students. Broken trajectory students reported using professors as the reference group to provide that same self-referential graduate student role legitimacy feedback. As noted earlier, this difference has the potential to significantly impact a students experience in, and satisfaction with, graduate school. 


\section{The Issue of Differences in Goals and Choices of Role Standards}

These last points having to do with students' relationships to professors brings up an interesting question: are the students who adopt a role standard closer to that of the professors really better served than those that do not? The answer may be that it depends on the students goals. Collier (2001), in his discussion of the differentiated model, explained why a range of different reference groups might exist for any given role by pointing to a quote from Peter Callero: "a role is only considered real to the degree that it is recognized, accepted and used to accomplish pragmatic interactional goals in a community (1994: 232)." Even though, as noted earlier, all these students were in terminal master's programs, the option for continuing their graduate education still exists. For students who are aiming to continue their education with a Ph.D., using the role standard of the professor may allow them to begin the socialization process of internalizing the role standard they will need to succeed at the next level. But for students whose goals are to enter the business world, perhaps a different role standard that emphasized different aspects of success would provide a more satisfying experience in graduate school.

\section{Benefits of Combining Methods of Qualitative Analysis}

One of the contentions of this study was that combining both thematic and narrative analysis of the interviews would allow for a complex story, like this research, to unfold in a way easier to understand than if only one method of analysis was employed. This contention was supported by the findings of this research. Using the 
two forms of analysis allowed for the discussion of perspectives and issues that would not have come up had only one of these methods been used.

Thematic analysis provided the ability to look for both inter- and intra-group themes and patterns. Underlying elements of the individual interviews were compared to look for components that showed up in multiple interviews. For the traditional / linear trajectory students, thematic analysis showed the intra-group challenges of academic advising. Thematic analysis also provided the framework for the finding that both groups of students found the broken trajectory students to be more serious as students.

Narrative analysis provided the framework to examine the form of the individual stories. This meant looking at how the story was told (e.g. with an active or a passive voice) as well as looking at how the story unfolds: was the story line stable (i.e. did not change over time), regressive (i.e. story became more negative over time) or progressive (i.e. story became more positive over time) (Gergen and Gergen, 1988). Looking at the direction of the storylines, narrative analysis showed that the common pattern for both groups of students for all of the themes was a progressive pattern, where the students felt more confident, connected and legitimate as they spent more time in their programs. Narrative analysis also provided the framework for the finding that the traditional / linear trajectory students entered the program with a sense of connection to their peers that was not present in the broken trajectory students.

\section{Theory Level Implications}

Since it appears that traditional / linear trajectory and broken trajectory 
students use different role standards for the graduate student role, the question arises where the different role standards came from. As stated earlier, Burke has expressed that the standards may come from prior socialization (Tushima and Burke, 1999), from the 'ought-self guide,' or the 'ideal-self guide' (Burke, 1996: 12), or from higher-level identity standards or principle level standards (Tushima and Burke, 1999). The fact that the two groups of students had a difference in time outside of schooling may support the 'prior socialization' argument, up to a point. The broken trajectory students have had the experience of being socialized outside of the academic environment, either through the work role or, for one of the participants, through the role of 'stay-at-home' mother. The question remains, however, whether a few years of difference can really have significant socialization affect compared to the length of similar academic socialization that both groups had up to and including their bachelor's programs. Another possible way of looking at these differences in standard is that having experiences outside of the academic environment shaped the expectations that these students had of themselves thereby changing the "ought-self" (the person that they feel they should be) or the "ideal-self" (the person that they feel they ideally want to be) guides that they used (Burke, 1996: 13). Burke states his belief that identity theory "needs to be modified to take these different types of standards (and perhaps others as well) into account" (1996: 14). Taking this research to the next level, it is possible to conjecture that experience outside of the academic arena opens the student up to encounters with individuals in a previously unknown reference group that then alters the student's perceptions of what is possible in ways 
that the students who move on a linear path through school do not experience.

\section{Implications for Models of Persistence}

As noted earlier, the current models of undergraduate higher education persistence may be somewhat limited in regards to explaining master's level persistence and degree completion. This research points to further challenges when applying these models to the broken trajectory students - returning adult students. Returning to Tinto's model of retention (see figure 1), it appears that broken trajectory students enter master's programs with heightened goal commitment compared to their traditional / linear trajectory peers. For master's students, the relationships that they have with professors are an important characteristic of being a successful graduate student and contribute to academic integration or connection. In this research, both the faculty and the broken trajectory students both seem to understand that relationships with faculty were necessary for successfully meeting academic goals. The question as to whether Tinto's model really fits for adult master's students seems to be related more to social integration relating to interactions with other students outside of the classroom. Differences in obligations, associated with non-academic roles, results in broken trajectory students having relatively less time to spend on university-related, non-academic actions. Considering the much higher, and more clearly articulated, motivations for completing the master's programs reported by the broken trajectory students, perhaps the operationalization of "involvement" that emphasizes the total number of hours spent in activities on-campus may not be relevant when considering 
the case of returning adult students. This brings up the question of whether the factors influencing goal commitment and institutional commitment are necessarily weighted the same for the master's level students as opposed to undergraduate ones.

\section{Program Level Implications}

While this study was exploratory in nature, the results still yield potential implications for graduate programs that are attempting to increase graduate student success. The clearest implication is the need for orientations for graduate students, preferably before the term begins. None of the students in this study remember a department orientation beyond a 'meet-and-greet' session. This produced anxiety for some of the students in both the traditional / linear trajectory students and the broken trajectory students. An orientation would not only increase understanding of department expectations of successful students, but it could also increase the feelings of connection that the students have toward their department. This increase in feelings of connection may in turn increase student and department satisfaction as well as retention rates.

It also seems to be important that departments, both collectively and on the individual faculty member level, explicitly articulate their expectations for graduate students at different points in the degree program as well as how students should proceed in order to meet those expectations. It also should be noted that since typically expectations of graduate student will change over time, the department has an obligation to inform students about changing expectations, as well as how to meet the 
revised expectations of the department. These expectations may need to be presented in different ways for the traditional / linear trajectory students and the broken trajectory students depending on the student's career and educational goals.

Overall, academic advising for graduate students needs improvement. In particular, students wanted guidance on fulfilling degree requirements and deadlines. There needs to be an approachable and a reliable place for information on successfully getting through the program. If the department's graduate adviser is too busy to actively engage with the students, then another solution needs to be found. In those cases, the advising duties should perhaps be split up among the faculty. If the advising is being split, but the personalities of the faculty are not a good fit with the duties of academic advising at this level, then perhaps an organized and personable faculty member should be put in charge of the departmental advising duties. Obviously the recommendation for improving academic advising needs to be department specific.

A possible solution for some of the advising is for the university's Student Affairs to expand their graduate student orientation. As one of the students in this study mentioned, this orientation is geared towards students who will be either research or teaching assistants. Encouraging all new graduate students to go to this would alleviate some of the questions that would be best answered on the university level (such as campus resources and university organizations).

Recognizing that different students have different concerns entering a master's program, departments and faculty need to be cognizant of how they frame expectations of students as well as how they respond to their student's performances. 
The needs of individual graduate students will by nature be idiosyncratic, but being aware that the educational trajectory that students have followed may influence students' understanding of their success, professors and departments can begin a discussion on how to best meet their students' needs.

\section{Limitations}

There are a variety of limitations within this research. The most obvious two are that the research was conducted at only one university, Portland State University, and there were a limited number of participants. These both affect the transferability of the findings. Lincoln and Guba (1985: 297-8) define transferability as the degree to which a researcher can argue that her findings will be useful for others in similar situations, with similar research questions or questions of practice. Therefore the findings of this study may be relevant to understanding the factors that impact master's degree completion in similar colleges and universities.

In addition, while this study was focusing on graduate students, it is possible that the findings can be used to understand how people develop understanding of new roles in other situations. Workers who have made a mid-career change may have some similar challenges as the broken trajectory students have, especially in their choice of reference groups. Being aware that these people may have a different idea of who is an appropriate reference group can help managers transition the new worker into the culture of the business. 
The participants all identified themselves as Caucasian, but until further research is done, it is unknown if this factor limits how the results can be generalized to students of other races or ethnicities. Another possible limiting factor is that these students self-selected to participate, which may mean that they are not representative of the general master's student body within the College of Liberal Arts and Sciences. These possible limitations are important to consider before making transferability statements, but they do not decrease the potential implications of this research; it just points to the need for further study.

A limitation that the researcher struggled with is how to present the data unbound by researcher influence. Qualitative data has a subjectivity to it that numbers and statistics do not. This subjectivity comes in at many different places, including during collection of the data, analysis of the data, and in the writing. Ultimately, the decision was to accept this limitation as reality and approach it ethically through full disclosure that the researcher was a broken trajectory student.

One of the goals for this research was to understand not only how graduate students dealt with discrepancy between their standard of graduate student and their performance, but to see if there was any difference between traditional / linear trajectory students and broken trajectory students in regards to how they attribute their success. This unfortunately did not come out in these interviews; perhaps because of the sample size, the self-selection of the participants, or possibly because of the interview questions themselves. Based on the literature, it was originally suggested that the broken trajectory students would be more likely to attribute success to 
external, personal characteristics rather than to their own ability based on the literature of both attribution theory and the Imposter Phenomenon. Although there were differences between the groups, it is not possible to tell from these interviews if the broken trajectory students recognized that they were using a successful standard of 'graduate student' compared to the traditional / linear trajectory students. If the broken trajectory students did recognize their success, it was also not possible to determine if they understood their success to be from a greater mastery of the graduate student role or from personal characteristics.

\section{Future Research}

There are a number of interesting directions that this research could go in during future research. Since this study was conducted only within the College or Liberal Arts and Sciences at Portland State University, it would be interesting to expand it to include other colleges within Portland State, such as Education or Social Work, where the certification leads towards specific careers. This would allow the researcher to explore the possibility that students' understanding of the graduate student role is affected by how the structural and philosophical set up of the college they are attending.

Portland State is a large university in an urban setting which has unique challenges and resources for students only available in this setting. It would be informative to replicate and expand the same study in other universities in different settings such as smaller campuses, rural campuses or private colleges. When discussing doctoral persistence, Tinto claims that: 
"it is possible to visualize the process of doctoral persistence as reflecting an interactive series of nested and intersecting communities not only within the university, but beyond it to the broader intellectual and social communities of students and faculty that define the norms and structure of the field of study at a national level...Graduate persistence is, at one and the same time, both more local and more national in character than is undergraduate persistence" (Tinto, $1993 ; 234)$

Not only would studying the same phenomenon at different settings allow for greater understanding of the master's student role, but it would open the possibility of teasing out the extent of the 'national' character of the graduate student role.

Due to the fact that this study only included successful graduate students (those that were in their second year of their program), it would be very informative to look at students who were not successful in completing the first year of their program. It would be interesting to see if there were more similarities or differences between the trajectories of education or between the successful and unsuccessful students. This could lead to policy recommendations for increasing master's student success and increased retention.

Another interesting direction for future research would be to compare how the students perceive themselves compared to how the faculty in their departments perceive them. This could shed some light on the development of the student-faculty interactions that researchers such as Astin and Tinto have shown to be so important for satisfaction and retention. 


\section{Conclusion}

Within education, most research that has focused on returning students has only done so at the undergraduate level. This indicates that there may be a group of returning students, those at the master's level, who may have different issues and concerns than their undergraduate counterparts.

In this study a qualitative design was used to explore how different paths through education impact master's level student's experiences, especially in relation to confidence in completing their program, feelings of connection to their department, and feelings of legitimacy. What this study found is that all of the students experienced apprehension during their first term in graduate school, and that different groups of students seemed to use slightly different role standards in directing their efforts to complete their master's degree programs. Interestingly, even when students were successful in graduate school, the students who had taken a break in their education seemed to have a different understanding of their success in graduate school than the students who did not take a break in their education. However, in the end, it was not possible to ascertain to what the different groups of students attributed their success. The transition to graduate school involves taking on a new role for all students, and this research shows that differences in students' educational path seems to affect this process. 


\section{References}

Astin, A.W. (1984). Student involvement: A developmental theory for higher education. Journal of College Student Personnel, 25, 297-307.

Astin, A.W. (1993). What matters in college? Four critical years revisited. San Francisco: Jossey-Bass.

Astin, A. W. (1999). Student Involvement: A Developmental Theory for Higher Education. Journal of College Student Development, 40(5), 12.

Aycock, G. (2003). Support Needed by Adult Learners to Accomplish Educational Goals in Higher Education. Unpublished Dissertation, North Carolina State University, Raleigh.

Bar-Tal, D. (1978). Attributional Analysis of Achievement-Related Behavior. Review of Educational Research, 48(2), 259-271.

Bar-Tal, D., \& Darom, E. (1979). Pupils' Attribution of Success and Failure. Child Development, 50(1), 264-267.

Brookfield, S. D. (1999). What is College Really Like for Adult Student? About Campus, 5.

Bryant, A., \& Charmaz, K. (Eds.). (2007). The Sage Handbook of Grounded Theory. Thousand Oaks: Sage Publications.

Burke, P. (1991). Identity Processes and Social Stress. American Sociological Review, $56,14$.

Burke, P. J. (1996). Social Identities and Psychosocial Stress. In Howard B. Kaplan (Ed.), Psychosocial Stress: Perspectives on Structure, Theory, Life Course, and Methods. Orlando: Academic Press.

Callero, P. L. (1994). From Role-Playing to Role-Using: Understanding Role as Resource. Social Psychology Quarterly, 57(3), 228-243.

Chickering, A. W., \& Reisser, L. (1993). Education and Identity (2nd ed.). San Francisco: Jossey-Bass Publishers.

Clance, P. R. (1985). The Imposter Phenomenon: Overcoming the Fear that Haunts Your Success. Atlanta, Georgia: Peachtree Publishers, Ltd. 
Clance, P. R., \& Imes, S. (1978). The Imposter Phenomenon in High Achieving Women: Dynamics and Therapeutic Intervention. Psychotherapy Theory, Research and Practice, 15(3).

Collier, P. (2001). A Differentiated Model of Role Identity Acquisition. Symbolic Interaction, 24(2), 217-235.

Collier, P., and Morgan, D. (2007). "Is That Paper Really Due Today?": Differences in First-Generation and Traditional College Students' Understanding of Faculty Expectations. Higher Education, 20.

Crittenden, K. (1983). Sociological Aspects of Attribution. Annual Review of Sociology, 9, 425-447.

Denzin, N. K., \& Lincoln, Y. S. (Eds.). (2005). The Sage Handbook of Qualitative Research (3rd ed.). Thousand Oaks: Sage Publications.

Devlin, M. (2002). Taking Responsibility for Learning isn't Everything: A Case for Developing Tertiary Students' Conceptions of Learning. Teaching in Higher Education, 7(2), 14.

Fairfield, H. (2007, September 12, 2007). Master's Degrees Abound as Universities and Students See a Windfall. The New York Times.

Feldman, K. A., Smart, J. C., \& Ethington, C. A. (1999). Major Field and PersonEnvironment Fit: Using Holland's Theory to Study Change and Stability of College Students. The Journal of Higher Education, 70(6), 642-669.

Freeman, M., daMarrais, K., Preusske, J., Roulston, K., \& St. Pierre, E. A. (2007). Standards of Evidence in Qualitative Research: An Incitement to Discourse. Educational Researcher, 36(1), 25-32.

Fried-Buchalter, S. (1997). Fear of Success, Fear of Failure, and the Imposter Phenomenon Among Male and Female Marketing Managers. Sex Roles: A Journal of Research, 37(11), 847-858.

Fruhan, G. A. (2002). Understanding Feelings of Fraudulence in the Early Professional Lives of Women. Massachusetts School of Professional Psychology.

Galbraith, M. W. (1998). Becoming an Effective Teacher of Adults. In M. W. Galbraith (Ed.), Adult Learning Methods (2nd ed.). Malabar, FL: Krieger Publishing Co. 
Gaylord, M. (2000). On the Outside Looking In: Some Thoughts About the MA Degree. PMLA, 115(5), 3.

Gergen, K., \& Gergen, M. (1983). Narratives and Self as Relationship. In T. Sarbin \& K. Scheibe (Eds.), Studies in Social Identity. New York: Praeger.

Gergen, K., \& Gergen, M. (1988). Narrative and the Self as Relationship. Advances in Experimental Social Psychology, 21, 40.

Gergen, M. (1988). Narrative Structures in Social Explanation. In C. Antaki (Ed.), Analysing Everyday Explanation: A Casebook of Methods. London: Sage Publications.

Giordano, M. (2000). Revaluing the Master's Degree. PMLA, 115(5), 3.

Girves, J., \& Wemmerus, V. (1988). Developing Models of Graduate Student Degree Progress. The Journal of Higher Education, 59(2), 27.

Goleman, D. (1984, September 11, 1984). Therapists Find Many Achievers Feel They're Fakes. The New York Times.

Gregg, W. E. (1972). Several Factors Affecting Graduate Student Satisfaction. The Journal of Higher Education, 43(6), 483-498.

Guest, G., Bunce, A., \& Johnson, L. (2006). How Many Interviews Are Enough?: An Experiment with Data Saturation and Variability. Field Methods, 18(1), 59-82.

Guevara, H. (2006). Exploring the Transition Experiences of New Graduate Students at Portland State University. Portland State University, Portland.

Hunter, M., \& Barker, G. (1987). "If at First...": Attribution Theory in the Classroom. Educational Leadership, 50-53.

Kasworm, C. E. (2003). Setting the Stage: Adults in Higher Education. New Directions for Student Services, 102, 3-10.

Kaufman, P., \& Feldman, K. (2004). Forming Identities in College: A Sociological Approach. Research in Higher Education, 45(5), 463-496.

Keith, B. (1999). The Institutional Context of Departmental Prestige in American Higher Education. American Educational Research Journal, 36, 409-445.

Keith, B., and Moore, H. A. (1995). Training Sociologists: An Assessment of Professional Socialization and the Emergence of Career Aspirations. Teaching Sociology, 23(3), 199-214. 
Kuh, G. D. (1995). The Other Curriculum: Out-of-Class Experiences Associated with Student Learning and Personal Development. The Journal of Higher Education, 66(2), 123-155.

Kuh, G. D., \& Hu, S. (2001). Learning Productivity at Research Universities. The Journal of Higher Education, 72(1), 1-28.

Lincoln, Y. S., \& Guba, E. G. (1985). Naturalistic Inquiry. Newbury Park: Sage Publications.

Lockwood, D. (1958). The Blackcoated Worker: A Study in Class Consciousness. London: Allen \& Unwin.

Lundberg, C. A. (2003). The Influence of Time-Limitations, Faculty, and Peer Relationships on Adult Student Learning: A Causal Model. The Journal of Higher Education, 74(6), 665-688.

Lundberg, C. A. (2004). Working and Learning: The Role of Involvement for Employed Students. NASPA Journal, 41(2), 201-215.

McCall, George J. and J.L. Simmons (1966). Identities and Interactions. New York: Free Press.

Mead, G. H. (Ed.). (1934). Mind, Self, \& Society: From the Standpoint of a Social Behaviorist (Vol. 1). Chicago: The University of Chicago Press.

Merriam, S. B., Caffarella, R. S., \& Baumgartner, L. M. (2007). Learning in Adulthood: A Comprehensive Guide (3rd ed.). San Francisco: Jossey-Bass.

Morgan, D. (1993). Qualitative Content Analysis: A Guide to Paths Not Taken. Qualitative Health Research, 3(1), 10.

Morgan, D. (1997). Focus Groups as Qualitative Research (second ed. Vol. 16). Thousand Oaks: Sage Publications.

O'Donnell, V., \& Tobbell, J. (2007). The Transition of Adult Students to Higher Education: Legitimate Peripheral Participation in a Community of Practice. Adult Education Quarterly, 57(4), 17.

Parelius, A. P. (1979). Age Inequality in Educational Opportunity: the Needs of Adult Students in Higher Education. Adult Education Quarterly, 29(3), 180-193. 
Parr, J. (1998). Theoretical Voices and Women's Own Voices: The Stories of Mature Women Students. In J. Ribbens \& R. Edwards (Eds.), Feminist Dilemmas in Qualitative Research: Public Knowledge and Private Lives. London; Thousand Oaks, Ca: Sage Publications.

Pascarella, E. T., Terenzi, P. T., \& Hibel, J. (1978). Student-Faculty Interactional Settings and Their Relationship to Predicted Academic Performance. The Journal of Higher Education, 49(5), 450-463.

Piliavin, J. A., Grube, J. A., \& Callero, P. L. (2002). Role as Resource for Action in Public Service. Journal of Social Issues, 58(3), 469-485.

Plimmer, G., and Schmidt, A. (2007). Possible Selves and Career Transition: It's Who You Want to Be, Not What You Want to Do. New Directions for Adult and Continuing Education, 114, 61-74.

Portland State University Office of Institutional Research and Planning (2008) http://www.oirp.pdx.edu/source/fact08w/factw084.htm accessed 05-02-08.

Powell, W. W., \& Snellman, K. (2004). The Knowledge Economy. Annual Review of Sociology, 30(1), 199-220.

Pusser, B., Breneman, D., Gansneder, B., Kohl, K., Levin, J., Milam, J., and Turner, S. (2007). Returning to Learning: Adults' Success in College is Key to America's Future: Lumina Foundation for Education.

Quinnan, T. W. (1997). Adult Students "At-Risk": Culture Bias in Higher Education. Westport: Bergin and Garvey.

Reis, S. (1987). We Can't Change What We Don't Recognize: Understanding the Special Needs of Gifted Females. Gifted Child Quarterly, 31(2), 7.

Reissman, C.K. (1993). Narrative Analysis (Vol. 30). Newbury Park: Sage Publications.

Riley, T., \& Hawe, P. (2005). Researching Practice: The Methodological Case for Narrative Inquiry. Health Education Research, 20(2), 15.

Shanahan, M. J. (2000). Pathways to Adulthood in Changing Societies: Variability and Mechanisms in Life Course Perspective. Annual Review of Sociology, 26, 667692.

Simons, L., Lathlean, J., \& Squire, C. (2008). Shifting the Focus: Sequential Methods of Analysis with Qualitative Data. Qualitative Health Research, 18(1), 13. 
Sissel, P. A., Hansman, C. A., \& Kasworm, C. E. (2001). The Politics of Neglect: Adult Learners in Higher Education. New Directions for Adult and Continuing Education, 91, 17.

Stryker, S., \& Serpe, R. (1982). Commitment, Identity Salience and Role Behavior: Theory and Research Example. In W. Ickes \& E. S. Knowles (Eds.) Personality, Roles, and Social Behavior. New York: Springer-Verlag.

Terenzi, P. T., Theophilides, C., \& Lorang, W. G. (1984). Influences on Students' Perceptions of Their Academic Skill Development during College. The Journal of Higher Education, 55(5), 621-636.

Tinto, V. Research and Practice of Student Retention: What Next? Journal of College Student Retention: Research, Theory \& Practice, 8(1), 1-20.

Tinto, V. (1975). Dropout From Higher Education: A Theoretical Synthesis of Recent Research. Review of Educational Research, 45(1), 89-125.

Tinto, V. (1982). Limits of Theory and Practice in Student Attrition. The Journal of Higher Education, 53(6), 687-700.

Tinto, V. (1987). Leaving College: Rethinking the Causes and Cures of Student Attrition. Chicago: The University of Chicago Press.

Tinto, V. (1988). Stages of Student Departure: Reflections on the Longitudinal Character of Student Leaving. Journal of Higher Education, 59(4), 17.

Tinto, V. (1993) Leaving College: Rethinking the Causes and Cures of Student Attrition (Second ed.). Chicago: The University of Chicago Press.

Tinto, V. (1997). Classrooms as Communities: Exploring the Educational Character of Student Persistence. The Journal of Higher Education, 68(6), 599-623.

Tinto, V. (1998). Colleges as Communities: Taking Research on Student Persistence Serviously. The Review of Higher Education, 21(2), 11.

Tirri, K., \& Koro-Ljungberg, M. (2002). Critical Incidents in the Lives of Gifted Female Finnish Scientists. Journal of Secondary Gifted Education, 13(4), 14.

Turner, R. H. (1978). The Role and the Person. The American Journal of Sociology, 84(1), 1-23. 
Weiner, B. (1972). Attribution Theory, Achievement Motivation, and the Educational Process. Review of Educational Research, 42(2), 203-215.

Weiner, B. (1979). A Theory of Motivation for Some Classroom Experiences. Journal of Education Psychology, 71(1), 23.

Weiner, B. (1986). An Attributional Theory of Motivation and Emotion. New York: Springer-Verlag.

Witherspoon, D., \& Nickell, E. (1991). Back to School at my Age?: A Guide for Both the Returning Student and the College Administrator. Lanham: University Press of America, Inc.

Zoltanski, J. (1995). Departure and Persistence: Exploring Student Experiences at the Master's Level. Portland State University, Portland. 
APPENDIX I: INTERVIEW GUIDE 


\section{Interview Questions}

Can you tell me a little about your academic experience in high-school?

When did you graduate High-School?

Did you plan on getting an advanced degree when you were in HS?

Can you tell me a little about your academic experience getting your bachelors?

Did you start right after high-school?

If no, what did you do before going back to school?

When did you start?

When did you complete?

Did you attend the same school throughout?

What type of school (private/public, 2 year/4 year, big/little, urban/rural)

Did you go directly from your bachelor's to your master's or did you take a break?

If you took a break - what did you do?

Did you plan on getting an advanced degree when in college?

Let's move on to your master's program...

Why did you decide to get your master's?

Why did you decide to apply to PSU?

What program are you in?

Did you apply anywhere else?

How did you choose which program to accept?

Let's focus for a minute on what it was like when you started your program.

Can you tell me about how you felt during those first few days?

What was the experience like?

What do you especially remember (what sticks in your mind)?

Probe for experiences

Was there orientation?

If yes, how was it organized (ie who facilitated, how long, who attended)

What can you remember feeling during the first few days?

What did you think the professors expected of you at that point?

What did you think that your peers expected of you?

How about other significant people in your life (family/friends)?

What did they expect?

Did you feel confident that you could meet these expectations?

Did you feel like you belonged in the department? 
Can you give an example why (or why not)? How did you feel about yourself as a "graduate student"? At that point, what did you think was going to be the hardest part of being a graduate student?

Let's move on to the end of the first quarter...

What can you remember feeling at the end of the term?

What did you think the professors expected of you at that point?

What did you think that your peers expected of you?

How about other significant people in your life (family/friends)?

What did they expect?

Did you feel confident that you could meet these expectations?

Did you feel like you belonged in the department?

Can you give an example why (or why not)?

How did you feel about yourself as a "graduate student"?

At that point, what did you think was going to be the hardest part of being a graduate student?

Now we are going to try something. Here is a graph. On this side ( $x$-access) there is a scale from very unsure up to very confident. On this side ( $y$-access) there are time periods. Can you walk me through how confident you felt about your ability to complete your program at these different times.

Probes: that is interesting - can you tell me more about..... what happened to make this difference...

If these don't come up - ask

Professors...

Peers

Family/friends

Mentors / support networks

Choosing thesis

Choosing chair / committee

We are going to do the same thing, but this time walk me through how well connected to the department you felt. Here is the graph. On this side ( $x$ access) there is a scale from very unattached to your department up to very connected to your department. On this side (y-access) there are again time periods.

Probes: that is interesting - can you tell me more about... what

happened to make this difference...

If these don't come up - ask

Professors... 
Peers

Family/friends

Mentors / support networks

Choosing thesis

Choosing chair / committee

We are going to do the same thing one last time, but this time walk me through how you felt as a student. Here is the graph. On this side ( $x$-access) there is a scale from "I felt like I am not really supposed to be a graduate student" to "I felt like a legitimate graduate student." On this side ( $y$-access) there are again time periods.

Probes: that is interesting - can you tell me more about..... what happened to make this difference...

If these don't come up - ask

Professors...

Peers

Family/friends

Mentors / support networks

Choosing thesis

Choosing chair / committee

Alright, now we want to talk about your experiences compared to others in your program. How are your experiences in graduate school similar to others in your program? How are your experiences different?

Some students go directly through from high-school to their bachelor's and then their master's, where others take a break in their educational path.

How do you think the path that you took helped you?

How do you think the path that you took hindered you?

Do you think that the path that you took changed the way you see yourself as a student? How?

Just a couple more questions to wrap up...

If everything works out they way you want it to, what will you be doing in five years?

If you could go back in time and give yourself one piece of advice about your academic career, what would it be?

Thank you for your candidness. Do you have anything else that you think I should know?

Once this interview is transcribed, would you want to look it over to add any clarifications? 


\section{APPENDIX II: GRAPHS}


Changes Over Time in How Confident You Felt About Completing the Program

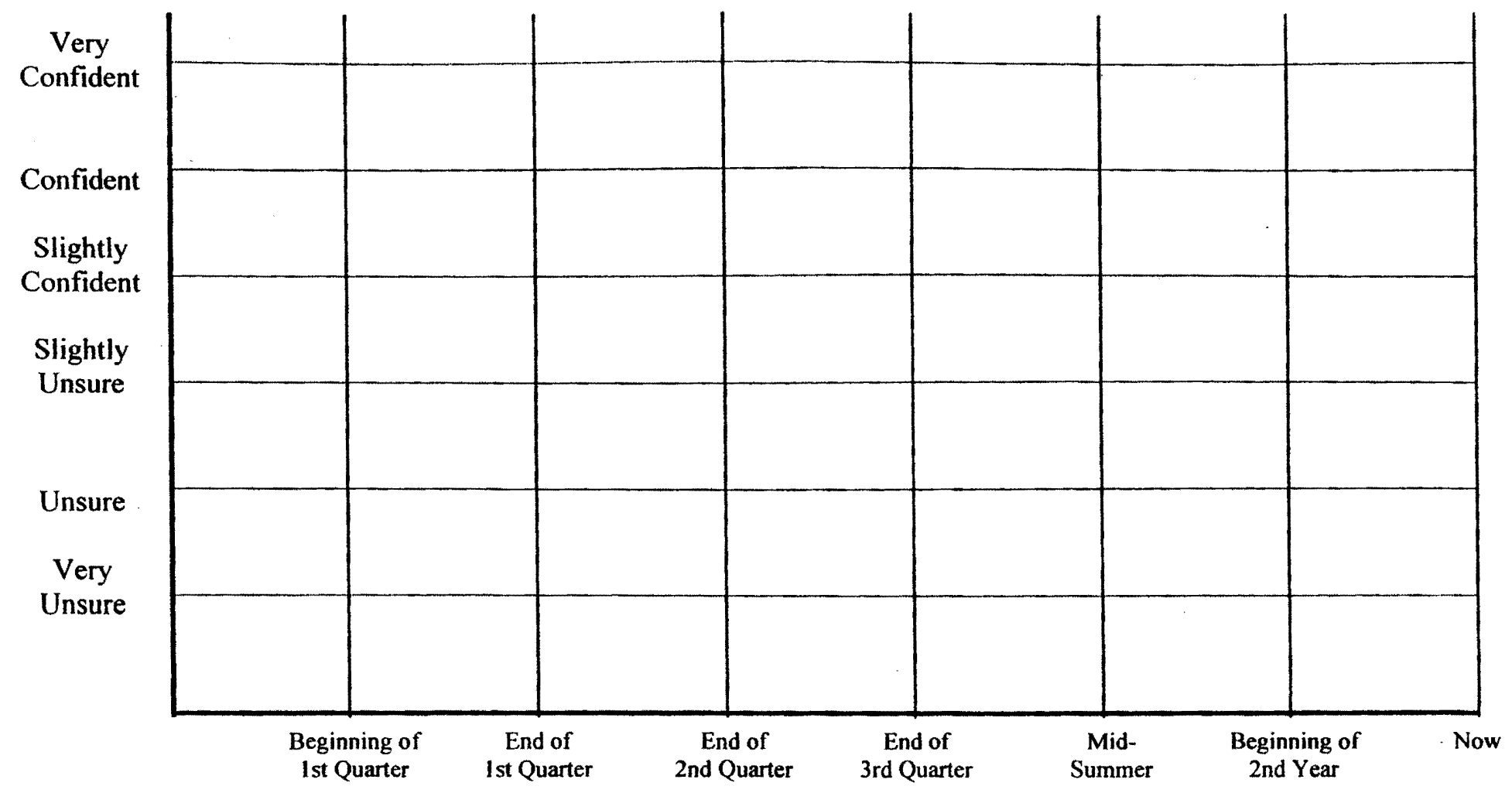


Changes Over Time in How Connected You Felt to Your Department

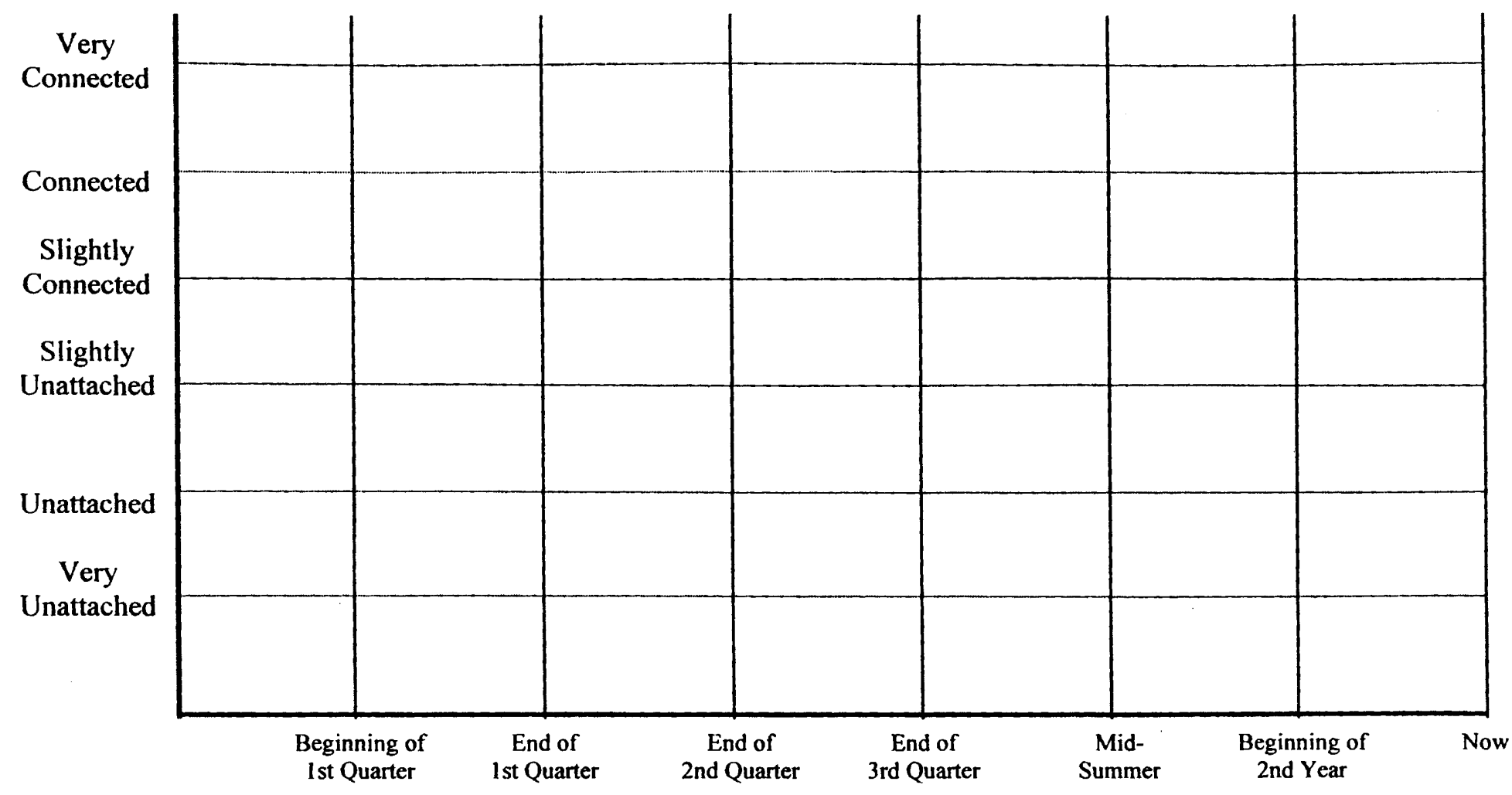




\section{Changes Over Time in How Legitimate You Felt as a Graduate Student}

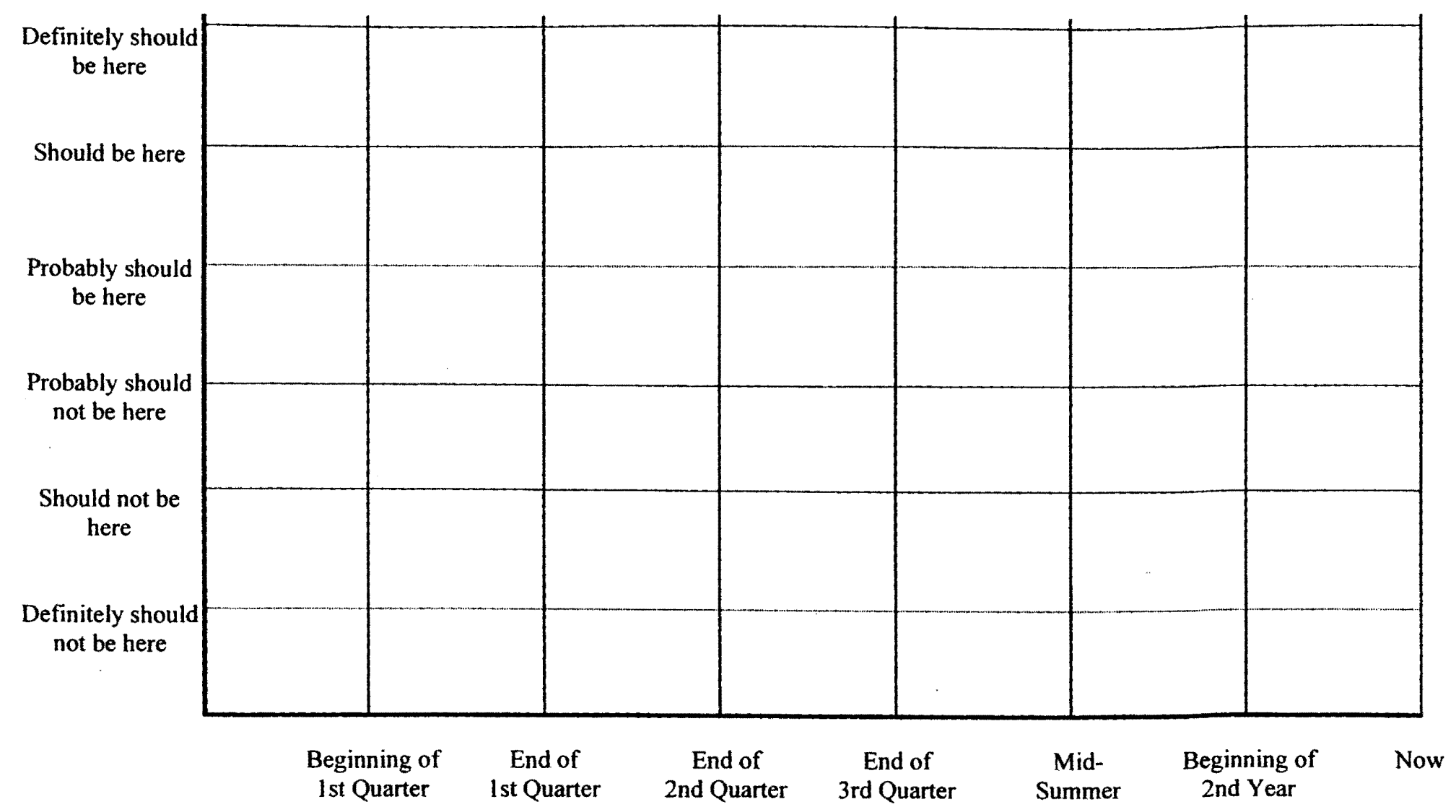




\section{Short Survey}

Name (this is only for my records, your name will not appear in any reports)

Department

Age Gender

Race or Ethnicity

Mother's highest level of education

Father's highest level of education

When and where did you graduate from high-school

$\overline{\text { When, where and in what department did you receive your Bachelor's degree }}$

Number of people you live with and your relationship to them

You have (check any that apply):

Financial responsibility

(it is necessary for you to contribute financially in some way)

Spouse / Partner

Child/ Children

Parent, sibling, or other adult

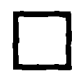

Physical/emotional responsibility (they live with you or you are a primary caretaker)
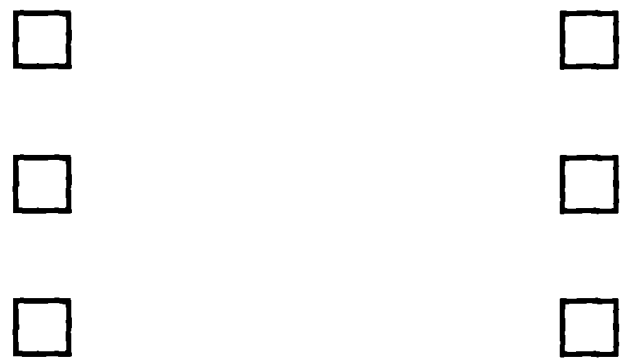
APPENDIX IV: INFORMED CONSENT FORM 


\section{Informed Consent Form}

You are invited to participate in a research study conducted by Tina Burdsall from Portland State University, Sociology Department. The researcher hopes to learn how master level students view their educational experiences at PSU. This study is also being conducted for partial fulfillment of the requirements for a master's degree. This study is under the supervision of Pete Collier, Associate Professor.

You were selected as a possible participant in this study because you are currently enrolled in a master's program at PSU. If you decide to participate, you will be asked to participate in a single interview, and fill out a short survey. The interview will last approximately 60 minutes, including the time it takes to fill out the survey. The interview will be audio-taped and notes will also be taken during the interview.

While participating in this study, it is possible that you may feel anxiety or embarrassment, but it is not anticipated that you will feel any more discomfort than you experience in the course of a normal day. If at any time you feel uncomfortable, you may opt out of any questions that you would like.

You may not receive any direct benefit from taking part in this study, but the study may help to increase knowledge which may help others in the future. It is also possible that you will enjoy and therefore benefit from thinking through your experiences at PSU.

Any information that is obtained in connection with this study and that can be linked to you or identify you will be kept confidential. A thesis will be written based on the information gained from these interviews, but pseudonyms will be assigned and any readily identifiable traits will be excluded. The audio-recordings will be kept on my personal computer, which is strictly password coded and kept in a secure location at all times. All hard-copies will be kept in a locked drawer in an office in the Sociology Department.

Your participation is voluntary. You do not have to take part in this study, and it will not affect your relationship with Portland State University nor your department. You may also withdraw from this study at any time without affecting your relationship with PSU or your department.

If you have concerns or problems about your participation in this study or your rights as a research subject, please contact:

Human Subjects Research Review Committee

Office of Research and Sponsored Projects,

111 Cramer Hall

Portland State University

503-725-4288 / 1-877-480-4400.

If you have questions about the study itself, contact Tina Burdsall or Pete Collier at:

Sociology Department

217 Cramer Hall

Portland State University

503-725-3926

Your signature indicates that you have read and understand the above information and agree to take part in this study. Please understand that you may withdraw your consent at any time without penalty, and that, by signing, you are not waiving any legal claims, rights or remedies. The researcher will provide you with a copy of this form for your own records. 